ГИПОГЛИКЕМИИ И РИСК КОГНИТИВНЫХ НАРУШЕНИЙ И ДЕМЕНЦИИ

У БОЛЬНЫХ ПОЖИЛОГО И СТАРЧЕСКОГО ВОЗРАСТА С САХАРНЫМ

ДИАБЕТОМ 2 ТИПА

○ О.Д. Остроумова ${ }^{1,2}$, Е.В. Суркова ${ }^{3}$, И.В. Голобородова', А.В. Стародубова ${ }^{4,5}$, А.И. Кочетков ${ }^{5,6}$, Т.Д. Кикнадзе4, Г.Р. Галстян

${ }^{1}$ Московский государственный медико-стоматологический университет им. А.И. Евдокимова, Москва

2Первый Московский государственный медицинский университет им. И.М. Сеченова (Сеченовский Университет), Москва

${ }^{3}$ Национальный медицинский исследовательский центр эндокринологии, Москва

${ }^{4}$ Федеральный исследовательский центр питания, биотехнологии и безопасности пищи, Москва

${ }^{5}$ Российский национальный исследовательский медицинский университет имени Н.И. Пирогова, Москва

6Российский геронтологический научно-клинический центр, Москва

Результаты исследований показывают, что неудовлетворительный гликемический контроль и рецидивирующие эпизоды тяжелой гипогликемии ассоциированы со снижением когнитивных функций у пожилых людей с сахарным диабетом 2 типа (СД2). С другой стороны, пациенты с СД2, ассоциированным с когнитивными расстройствами/деменцией, оказываются наиболее подверженными риску развития гипогликемических состояний. Очевидно, что взаимосвязь между гипогликемией и деменцией весьма сложна и носит двунаправленный взаимоотягощающий характер.

Исследования демонстрируют также, что лица старших возрастных групп с СД2 и когнитивными нарушениями (КН) обладают высоким риском развития гипогликемических состояний как нежелательных побочных явлений со стороны сахароснижающей терапии. При этом особый интерес представляет вопрос, активно изучающийся в настоящее время, касающийся влияния разных групп антидиабетических препаратов на когнитивный статус и скорость когнитивного снижения у больных СД с наличием КН.

В данном обзоре мы предприняли попытку обобщить, систематизировать и представить имеющиеся в литературе данные, касающиеся влияния гипогликемии на риск КН и деменции у больных пожилого и старческого возраста с СД2, а также степени участия в этом процессе различных групп антидиабетических препаратов.

КЛЮЧЕВЫЕ СЛОВА: гипогликемия; когнитивные нарушения; деменция; сахарный диабет; антидиабетические препараты

\title{
HYPOGLYCEMIA AND THE RISK OF COGNITIVE IMPAIRMENT AND DEMENTIA IN ELDERLY AND SENILE PATIENTS WITH TYPE 2 DIABETES
}

\author{
(c) Olga D. Ostroumova ${ }^{1,2 *}$, Elena V. Surkova ${ }^{3}$, Irina V. Goloborodova' ${ }^{1}$ Antonina V. Starodubova ${ }^{4,5}$, Alexey I. Kochetkov ${ }^{5,6}$, \\ Tamara D. Kiknadze ${ }^{4}$, Gagik R. Galstayn ${ }^{3}$
}

\begin{abstract}
${ }^{1}$ A.I. Yevdokimov Moscow State University of Medicine and Dentistry, Moscow, Russia, Moscow Russia
2I.M. Sechenov First Moscow State Medical University (Sechenov University), Moscow, Russia

${ }^{3}$ Endocrinology Research Centre, Moscow, Russia

${ }^{4}$ Federal Research Centre of Nutrition, Biotechnology and Food Safety, Moscow, Russia

${ }^{5}$ N.I. Pirogov Russian National Research Medical University, Moscow, Russia

${ }^{6}$ Russian Clinical and Research Center of Gerontology, Moscow, Russia
\end{abstract}

Research results show that poor glycemic control and recurrent episodes of severe hypoglycaemia are associated with a decrease in cognitive function in elderly people with type 2 diabetes mellitus (T2DM). On the other hand, patients with diabetes mellitus associated with cognitive impairment/dementia are most at risk of developing hypoglycaemic conditions. It is obvious that the relationship between hypoglycaemia and dementia is very complex and has a mutually aggravating nature.

Studies also show that individuals of older age groups with diabetes and cognitive impairment have a high risk of developing hypoglycaemic conditions, such as unwanted side effects from glucose-lowering therapy. In this case, of particular interest is the question that is being actively studied at the present time, which is concerning the effect of different groups of glucose-lowering antidiabetic drugs on the cognitive status and the rate of cognitive decline in diabetic patients with cognitive impairment.

In this review, we attempted to summarise, systematise, and present data available in the literature concerning the effect of hypoglycaemia on the risk of cognitive impairment and dementia in elderly and senile patients with type- 2 diabetes, as well as the degree of participation in this process of of various groups of sugar-lowering antidiabetic drugs.

KEYWORDS: hypoglycemia; cognitive impairment; dementia; diabetes mellitus; antidiabetic drugs 
Вопросы старения в настоящее время находятся в фокусе особого внимания и рассматриваются в качестве приоритетных для изучения. Демографическая ситуация, сложившаяся в большинстве развитых стран мира, в том числе и в Российской Федерации, характеризующаяся ростом продолжительности жизни и снижением рождаемости, способствовала увеличению в структуре общей численности населения доли лиц пожилого и старческого возраста. Так, если в начале XX в. в развитых странах мира доля населения в возрасте 60 и более лет составляла лишь 4-5\%, то к настоящему времени этот показатель достиг уже 20-25\% [1]. В ближайшие несколько десятков лет дальнейшее «старение» населения продолжится: к 2050 г. доля лиц в возрасте 60 и более лет перешагнет 30\% рубеж в большинстве развитых стран мира [1]. По данным глобального отчета Age Watch (Global Age Watch Index 2015) [1], население России старше 60 лет в 2015 г. равнялось 28,7 млн человек, что составило около $22 \%$ от общей популяции. Прогнозируется, что к 2050 г. доля населения России в возрасте $\geq 60$ лет приблизится к 29\% [1].

Результатом демографического старения населения оказались многочисленные и разнообразные медицинские, социальные и экономические последствия, и одно из них - проблема когнитивных нарушений (KН) и деменции. Согласно данным ВО3, в 2015 г. во всем мире насчитывалось около 50 млн людей с деменцией [2]. Ежегодно регистрируется почти 10 млн новых случаев заболевания, и к 2050 г. ожидается увеличение численности больных с деменцией до 132 млн [2, 3]. Распространенность деменции тесно ассоциирована с возрастом: если частота ее выявления у лиц в возрасте $\geq 65$ лет не превышает 0,5\%, то у лиц в возрасте старше 75 лет она составляет уже 25\%, а среди тех, кто старше 85 лет, - около 60\% [3, 4].

Деменция - одна из основных причин инвалидизации пожилых людей во всем мире. На ее долю приходится 11,9\% лет, прожитых с инвалидностью, вызванной неинфекционными заболеваниями [5]. Выраженное снижение когнитивных функций, часто сопровождаясь поведенческими и психическими нарушениями, способствует быстрой бытовой, социальной и профессиональной дезадаптации лиц, страдающих деменцией. «Бремя» деменции оказывает влияние не только на самих пациентов, но и на членов их семей, на лиц, осуществляющих уход за ними, на их семьи и общество в целом. Резко растут и материальные затраты: так, в 2015 г. общий объем расходов на уход за больными деменцией в мире составил 818 млрд долл. США, а к 2030 г. ожидается рост этого показателя до 2 трлн долл. США [3].

Однако следует понимать, что развитие деменции происходит постепенно, в течение многих лет. В большинстве случаев до деменции отмечается появление когнитивных расстройств (КР), не достигающих степени деменции, то есть не приводящих к профессиональной, социальной и бытовой дезадаптации. К таким недементным КН относятся легкие и умеренные КР, которые представляют собой последовательные и плавно переходящие друг в друга стадии патологического процесса [6]. Распространенность недементных форм КН у лиц в возрасте $\geq 65$ лет составляет от 10,7\% до $14,9 \%[6,7,8]$, при этом у 15\% больных с недементными КН деменция развивается в течение 1 года, а у 55-70\% - в течение 4 лет [9].
Популяционные данные свидетельствуют о высокой степени соответствия тенденций динамики эпидемиологических показателей $\mathrm{KH}$ и сахарного диабета (СД). Так, в 2015 г. СД был диагностирован у 415 млн человек, в 2017 г. - у 425 млн человек (8,8\% популяции), а прогноз Международной диабетической федерации на 2045 г. предполагает увеличение числа больных СД до 629 млн человек (9,9\% популяции) [10]. Доля лиц старших возрастных групп (65-79 лет) в общей структуре заболеваемости СД в 2017 г. составила 23\%, а к 2045 году прогнозируется ее увеличение до $30 \%$ [10].

СД является фактором риска развития сосудистой деменции [11, 12], смешанной деменции, деменции при болезни Альцгеймера и умеренных КН $[13,14,15]$. Так, в ряде эпидемиологических исследований у больных СД 2 типа (СД2) обнаружено повышение риска развития $\mathrm{KH}$ и деменции до 40\% [14, 16, 17].

KН при СД развиваются как результат взаимодействия совокупности ряда патогенетических факторов: метаболических (гипер-, гипогликемия), сосудистых (ишемия, эндотелиальная дисфункция), эндокринных (гиперинсулинемия и инсулинорезистентность, гиперлептинемия, гиперкортизолемия) и неврологических факторов (церебральная атрофия), генетической предрасположенности [11].

Тяжесть КН и темпы их прогрессирования у больных СД варьируют в зависимости от возраста и типа диабета: у пациентов с СД2 в возрасте $\geq 60$ лет чаще встречаются умеренные КН и деменция [18, 19, 20]. Причем, прогноз в плане прогрессирования умеренных КН в деменцию у пациентов с СД2 хуже, чем у пациентов без СД. Так, результаты 2 крупных метаанализов показали, что у пациентов с умеренными КР и СД2 относительный риск (ОР) развития деменции составлял 1,7 (95\% доверительный интервал (ДИ) 1,1-2,4) [21] и 1,7 (95\% ДИ 1,1-2,6) [22] по сравнению с пациентами с умеренными КН без СД. А в исследовании Haroon и соавт. [23] выявлено, что у пациентов с недавно диагностированным СД2 риск деменции составлял 1,16 (95\% ДИ 1,15-1,18) [23] по сравнению с больными без СД. Установлено также, что деменция у пациентов с СД2 развивается в более молодом возрасте и чаще имеет сосудистый генез по сравнению с лицами без СД [24].

В свою очередь, КН снижают способность больных СД к адекватному контролю гипергликемии и увеличивают риск развития осложнений. Исследования показывают, что когнитивное снижение у пожилых людей с СД2 ассоциировано с неудовлетворительным гликемическим контролем и более частыми эпизодами тяжелой гипогликемии [25].

Уровень развития современной фармакотерапии СД2 позволяет достигать и эффективно поддерживать целевые значения гликемии и, соответственно, создавать условия для оказания дополнительного протективного воздействия в отношении сопутствующих состояний и осложнений, включая КР и деменцию. Однако некоторые нежелательные побочные реакции (НПР) при применении сахароснижающих препаратов, прежде всего гипогликемия, также ассоциированы с развитием КН и деменции.

Российские алгоритмы специализированной медицинской помощи больным сахарным диабетом приводят следующую классификацию гипогликемии [26]. 
Уровень 1: значения глюкозы плазмы от 3,0 до <3,9 ммоль/л (с симптомами или без) у больных СД, получающих сахароснижающую терапию, указывают на риск развития гипогликемии и требуют начала мероприятий по купированию гипогликемии независимо от наличия или отсутствия симптомов.

Уровень 2: значения глюкозы плазмы <3,0 ммоль/л, с симптомами или без - клинически значимая гипогликемия, требующая немедленного купирования.

Уровень 3: тяжелая гипогликемия - гипогликемия в пределах вышеуказанного диапазона с таким нарушением когнитивных функций (включая потерю сознания, т.е. гипогликемическую кому), которое требует помощи другого лица для купирования.

Литературные данные демонстрируют значительную вариабельность распространенности гипогликемии у больных СД, что обусловлено различиями в определениях понятия «гипогликемия» и методах регистрации, а также нередко неполной демографической и клинической характеристикой выборки и их различиями в разных исследованиях [27]. Кроме того, для пациентов старших возрастных групп существуют дополнительные трудности диагностики гипогликемических состояний. Именно у этой группы лиц классические для гипогликемии вегетативные симптомы, как правило, имеют малую выраженность или совсем отсутствуют, а имеющаяся симптоматика зачастую имитирует неврологические нарушения, или трактуется как прогрессирование деменции, или вообще не диагностируется, так как пациенты зачастую не сообщают о каких-либо симптомах при развитии эпизодов гипогликемии [27]. Это становится препятствием для определения истинной распространенности гипогликемических состояний у лиц пожилого и старческого возраста. Однако неоспоримым является тот факт, что у пациентов с СД2 старших возрастных групп частота гипогликемий выше, чем у более молодых лиц [27]. Так, в проспективном исследовании, включившем 3810 пациентов учреждений первичной медико-санитарной помощи с СД2 в возрасте $\geq 40$ лет, получавших терапию одним или несколькими пероральными сахароснижающими препаратами, частота развития эпизодов гипогликемии изучалась в 3 возрастных группах: <60 лет $(n=1253) ; \geq 60$ лет, но <70 лет $(n=1184)$ и $\geq 70$ лет $(n=1373)$. Согласно полученным результатам, $11 \%$ пациентов сообщили по крайней мере об одном эпизоде гипогликемии любой тяжести в течение 12 мес. Однако в группе больных в возрасте $\geq 70$ лет отмечалось большее количество эпизодов гипогликемии, чем у более молодых лиц ( $\geq 60$ лет, но <70 лет; <60 лет): 12,8\% против 10,1\% и 9,0\% соответственно $(\mathrm{p}<0,01)$ [28].

Высокий риск развития гипогликемии у лиц пожилого и старческого возраста обусловлен наличием у них провоцирующих факторов: преклонный возраст, недостаточное питание, терапия инсулином или препаратами сульфонилмочевины, гипогликемия в анамнезе, маскированная гипогликемия, мультиморбидность и, как следствие, полипрагмазия, хроническая печеночная или почечная недостаточность, перенесенный инсульт или транзиторная ишемическая атака, клинически значимая депрессия, хроническая сердечная недостаточность, пребывание в учреждениях долговременного ухода, недавняя госпитализация, социальная изоляция. Демен- ция также является одним из факторов риска развития гипогликемии [28]. Кроме того, наличие деменции увеличивает риск госпитализаций больных СД2 и, как следствие, расходов на здравоохранение [29]. Так, в исследовании W. Kaewput et al. [29], в котором приняли участие 11404 пациента с СД2, показано, что больные с наличием деменции нуждались в более частой госпитализации по сравнению с пациентами без деменции в случае развития гипогликемии (отношение шансов (ОШ) 6,27; 95\% ДИ 2,13-18,43; $p=0,001$ ) [29].

В свою очередь, частые эпизоды гипогликемии у пациентов старших возрастных групп представляют реальную опасность, так как способствуют появлению ряда неблагоприятных последствий, в том числе развитию КН и их прогрессированию вплоть до развития деменции [30]. В свете вышеизложенного особый интерес представляет вопрос о влиянии сахароснижающей терапии на скорость снижения когнитивных функций у больных СД с наличием КН, который в настоящее время активно изучается.

\section{СОСТОЯНИЕ КОГНИТИВНЫХ ФУНКЦИЙ У БОЛЬНЫХ СД2 В ЗАВИСИМОСТИ ОТ НАЛИЧИЯ В АНАМНЕЗЕ ЭПИЗОДОВ ГИПОГЛИКЕМИИ}

Имеющиеся в настоящее время немногочисленные данные клинических исследований, рассматривающих связь рецидивирующих эпизодов гипогликемии у больных СД2 с состоянием когнитивных функций, свидетельствуют о том, что пациенты с наличием подобных эпизодов в анамнезе имеют худшие показатели нейрокогнитивных тестов.

В метаанализе Chen и соавт. [31] изучали наличие и выраженность КН у больных СД с рецидивирующими эпизодами тяжелой гипогликемии. В метаанализ включено 7 исследований (одно проспективное, остальные 6 - ретроспективные), объединивших в общей сложности 4013 пациентов. Количество больных в исследованиях, включенных в данный метаанализ, варьировало

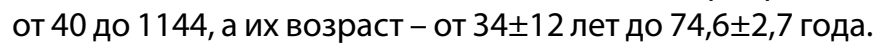
Из 7 исследований 3 включали только пациентов с СД 1 типа (СД1), 2 - только пациентов с СД2, одно исследование включало больных с обоими типами СД, и в одном не было информации о типе СД. Пациенты во всех исследованиях, включенных в метаанализ, были сопоставимы по возрасту и полу. Анализ когнитивных функций включал широкий спектр тестов с оценкой уровня интеллекта, памяти, скорости обработки информации, управляющих функций, психомоторной саморегуляции. Эпизоды гипогликемии в исследованиях, включенных в метаанализ, были выявлены путем анкетирования, интервьюирования участников и членов их семей, изучения баз данных медицинских учреждений.

Результаты метаанализа продемонстрировали, что у пациентов с рецидивирующими эпизодами тяжелой гипогликемии нарушение памяти было более выражено, чем у больных без таких эпизодов (стандартизованная разность средних (СРС) -0,16; 95\% ДИ -0,26--0,07; $\mathrm{p}=0,0005)$. При этом в $5[32,33,34]$ из 13 используемых тестов, оценивающих память, эта разница между группами была статистически значимой (СРС -0,52; 95\% ДИ -0,89--0,13), а в 3 из них $[32,33]$ статистиче- 
ски значимых различий между группами обнаружено не было. Однако при сравнении результатов этих 3 тестов у больных СД2 с наличием и отсутствием тяжелых гипогликемий было обнаружено, что пациенты с эпизодами тяжелой гипогликемии в анамнезе обладали меньшим объемом памяти (СРС -0,18; 95\% ДИ -0,30--0,06) в отличие от пациентов без подобных эпизодов. Скорость когнитивных процессов в целом по группам больных с/без тяжелых гипогликемических состояний статистически значимо не различалась между группами (СРС -0,13; 95\% ДИ -0,32-0,07; $=0$,20), однако анализ подгрупп пациентов с СД2 выявил, что низкая скорость обработки информации была статистически значимо ассоциирована с рецидивирующими эпизодами тяжелых гипогликемий (СРС -0,33; 95\% ДИ -0,48--0,18). При исследовании уровня интеллекта, психомоторной саморегуляции и управляющих функций статистически значимых различий между подгруппами не отмечено (СРС -0,05; 95\% ДИ -0,22-0,12; $\mathrm{p}=0,59$, СРС 0,19; 95\% ДИ -0,05-0,42; $\mathrm{p}=0,13$, СРС 0,01; 95\% ДИ -0,26-0,25; $p=0,97$ соответственно).

Полученные результаты позволили исследователям сделать вывод о том, что у больных СД2 с наличием тяжелых гипогликемий в анамнезе снижены память и скорость когнитивных процессов по сравнению с больными без таких эпизодов в анамнезе. По мнению авторов, это свидетельствует о наличии взаимосвязи между эпизодами тяжелых гипогликемий, особенно рецидивирующих, и когнитивным статусом у взрослых пациентов с СД. В то же время авторы обращают внимание на ряд ограничений, имеющих место в данном метаанализе, а именно: небольшое количество включенных в него исследований, а также малая выборка, небольшой период наблюдения в ряде исследований. Имеет значение и ретроспективный характер дизайна абсолютного большинства исследований, оценивающий влияние на когнитивный статус только тяжелых гипогликемических состояний, опираясь, в том числе, на ретроспективные самоотчеты пациентов (анкетирование пациентов), подразумевающие субъективный характер оценки и, возможно, неполный учет числа эпизодов гипогликемии. Имеет значение и то, что в ряде исследований, включенных в метаанализ, у пациентов имел место СД1 либо неизвестный тип СД. Таким образом, можно предположить, что имеющиеся ограничения характеризуют выявленную авторами связь, скорее, как ассоциацию - объединение, без уточнения причинно-следственных связей, их направленности, что, в свою очередь, требует дальнейших исследований в этой области.

В проспективном наблюдательном исследовании Feinkohl и соавт. [33] у 831 пациента с СД2 в возрасте

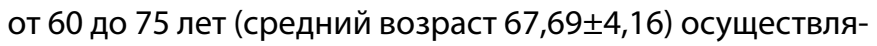
лась оценка когнитивных функций на исходном визите, а также через 4 года наблюдения. Средняя продолжительность СД2 составляла 6 лет, инсулинотерапию получали 16,7\% больных, производные сульфонилмочевины - 25,3\%. У 77 участников исследования в анамнезе были эпизоды гипогликемии, требовавшие посторонней помощи. Для оценки когнитивных функций авторы использовали ряд нейропсихологических тестов: субтест «лица» шкалы памяти Векслера (Faces Subtests of the Wechsler Memory Scaled Third Edition), логическая память (Logical Memory), тест вербальных ассоциаций Борков- ского (Borkowski Verbal Fluency Test), тест вербальных ассоциаций (Verbal Fluency Test), часть В теста построения маршрута (Trail Making Test Part B), последовательность цифр и букв (Letter-Number Sequencing), тест символьно-числового кодирования (Digit Symbol Coding), субтест матрицы теста Векслера (Matrix Reasoning (MR) subtests of the Wechsler Adult Intelligence Scaled Third Edition), словарная шкала Милл Хилл (junior and senior Mill Hill Vocabulary Scale). Результаты нейропсихологических тестов были объединены для получения интегрального показателя состояния когнитивных функций - «g». Сравнение когнитивных функций у больных СД2 с наличием/отсутствием эпизодов гипогликемии, потребовавших посторонней помощи, в анамнезе показало, что исходно интегральный показатель состояния когнитивных функций у больных с эпизодами гипогликемий в анамнезе (после коррекции на возраст и пол) был ниже, чем у пациентов без эпизодов гипогликемии: -0,08 (95\% ДИ -0,27-0,12) против 0,17 (95\% ДИ0,10-0,24), $\mathrm{p}=0,019$.

Исследование поперечного типа Edinburgh Tyре 2 Diabetes Study [32], объединившее 1066 больных СД2, средний возраст которых составлял 67,9+4,2 года, было направлено на определение взаимосвязи между тяжелыми гипогликемическими состояниями в анамнезе и когнитивными функциями. Длительность СД2 у включенных в исследование пациентов в среднем составляла 8,1 лет. Общее количество пациентов, сообщивших хотя бы об одном эпизоде тяжелой гипогликемии, составило 113, из них производные сульфонилмочевины получали 28\%. У 86 пациентов при опросе эпизоды тяжелой гипогликемии отмечены за год до тестирования когнитивных функций. Тяжелая гипогликемия определялась как состояние, требующее посторонней помощи. Когнитивные функции изучались с помощью ряда тестов, с последующим определением показателя «g»: «лица и семейные фотографии» и логическая память теста Векслера (Faces and Family Pictures subtest and Logical Memory from the Wechsler Memory Scale Third Edition), последовательность цифр и букв (Letter-Number Sequencing), матриксы и символьно-числовое кодирование из теста Векслера (Matrix Reasoning and Digit Symbol Test from the Wechsler Adult Intelligence Scale Third Edition), тест вербальных ассоциаций (Verbal Fluency Test), часть В теста построения маршрута (Trail-Making Test, Part B). Эмоциональный статус оценивали с использованием Госпитальной шкалы тревоги и депрессии (Hospital Anxiety and Depression Scale, HADS). Оценка интеллекта осуществлялась с помощью словарной шкалы Милл Хилл (combined junior and senior Mill Hill Vocabulary Scale).

В результате исследования было обнаружено, что пациенты, сообщившие хотя бы об одном эпизоде тяжелой гипогликемии, имели худшие показатели когнитивных функций по сравнению с больными без таких эпизодов в анамнезе («g»: -0,34 против 0,05, p<0,001), независимо от длительности заболевания, наличия сосудистых факторов риска или сердечно-сосудистых осложнений. Причем более низкие показатели когнитивных тестов соответствовали большему числу эпизодов гипогликемии в течение года до оценки когнитивных функций. Авторы сделали вывод о том, что наличие рецидивирующих тяжелых гипогликемий в анамнезе ассоциировано со снижением в последующем когнитивных функций, не- 
зависимо от длительности СД и наличия сердечно-сосудистых осложнений [32].

Таким образом, результаты исследований свидетельствуют о наличии связи между эпизодами тяжелых гипогликемий и худшим состоянием когнитивных функций; они демонстрируют, что больные СД2, имеющие в анамнезе эпизоды тяжелой гипогликемии, имеют худшие показатели при нейрокогнитивном тестировании. Однако исследователи констатируют необходимость проведения дальнейших проспективных исследований на эту тему, с большим объемом выборок и оценкой когнитивных функций больных СД2 в динамике, необходимых с целью уточнения характера взаимоотношений между тяжелыми гипогликемиями и состоянием когнитивного статуса, определения причинно-следственной направленности [32].

\section{ВЛИЯНИЕ ЭПИЗОДОВ ГИПОГЛИКЕМИИ НА РИСК РАЗВИТИЯ ДЕМЕНЦИИ И ТЕМПЫ ПРОГРЕССИРОВАНИЯ КОГНИТИВНЫХ НАРУШЕНИЙ/ДЕМЕНЦИИ}

Предполагают, что рецидивирующие и/или тяжелые эпизоды гипогликемии могут приводить и к прогрессированию когнитивных нарушений и развитию деменции, особенно у лиц старших возрастных групп [33]. Взаимосвязь между наличием эпизодов гипогликемии и риском развития деменции/прогрессирования КН изучалась в ряде исследований [23, 33-39].

\section{Метаанализы}

В метаанализ Mattishentand, Loke [34] было включено 9 проспективных и ретроспективных когортных исследований, объединивших 1439818 пациентов (средний возраст 75 лет) с СД2, принимающих сахароснижающие препараты. Для изучения взаимосвязи между эпизодами гипогликемий и риском когнитивного снижения были отобраны 5 исследований с количеством участников от 276 до 225 045. В 4 исследованиях длительность СД2 была более года, в одном из исследований СД2 охарактеризован как недавно диагностированный. Средний возраст участников составлял от 64,2 до 74 лет, в одном из исследований возраст участников был обозначен как $\geq 65$ лет. Все участники получали сахароснижающую терапию (инсулин или пероральные сахароснижающие препараты), от 37,75\% до 76\% больных с гипогликемическими эпизодами находились на инсулинотерапии. В одном из исследований данных о процентном соотношении используемых сахароснижающих препаратов не было предоставлено. Учет гипогликемических событий основывался на результатах самоотчетов участников, а также на исследовании баз данных медицинских учреждений, страховых компаний. Период наблюдения в разных исследованиях составлял от 3 до 27 лет. В результате проведения метаанализа обнаружено статистически значимое повышение риска деменции у больных с наличием гипогликемических событий (объединенное ОШ 1,68; 95\% ДИ 1,45-1,95) по сравнению с пациентами с СД2 без гипогликемических состояний в анамнезе.

Проспективные (наблюдательные) исследования

Haroon и соавт. [23] наблюдали за 225045 больными (средний возраст 73 года) с недавно диагностированным СД2. Наиболее часто в качестве сахароснижающей тера- пии были использованы инсулин, метформин и производные сульфонилмочевины. Целью исследования было изучить, является ли СД2 у больных пожилого возраста фактором риска развития деменции. Одной из задач исследования было выявление предикторов развития деменции у больных СД2, в том числе оценивали роль эпизодов гипогликемии. Средний период наблюдения составил 7,2 года. В результате исследования обнаружено, что у больных СД2 наличие эпизодов гипогликемии, требовавших неотложной помощи или госпитализации, было ассоциировано с более высоким риском развития деменции (ОШ 1,73; 95\% ДИ 1,62-1,84).

Yaffe и соавт. [35] также изучали возможную взаимосвязь между эпизодами гипогликемии и деменцией. Авторы обследовали 783 пожилых пациента с СД негроидной и европеоидной расы, ни у кого из них на момент включения в исследование не было КН. Средний возраст больных составлял 74,0 2,8 года, 47,6\% из них составляли женщины. Из 783 пациентов 455 умерли в течение периода наблюдения (12 лет). За период наблюдения у 61 больного СД2 был как минимум один эпизод гипогликемии, потребовавший госпитализации (у 21 пациента - >1 эпизода тяжелой гипогликемии), 95\% больных СД2 с эпизодами гипогликемии находились на инсулинотерапии. У 148 больных в течение периода наблюдения развилась деменция. Сравнение групп больных с наличием/отсутствием эпизодов тяжелой гипогликемии выявило двукратное увеличение риска развития деменции у больных СД2 с наличием гипогликемии по сравнению с пациентами без подобных эпизодов в анамнезе (ОШ 2,1; 95\% ДИ 1,0-4,4). Частота развития деменции в случае наличия эпизодов гипогликемии составила $34,4 \%$ (у 21 больного из 61) по сравнению с 17,6\% (127 пациентов из 722) среди тех, у кого эпизоды гипогликемии за период наблюдения отсутствовали $(\mathrm{p}<0,001)$.

В исследование Chin et al. [36] были включены 1957 больных в возрасте $\geq 60$ лет (средний возраст

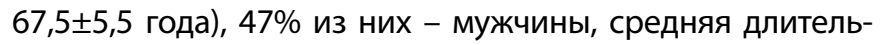
ность СД2 - 7,8 7,5 лет. Ни у кого из включенных больных не было эпизодов гипогликемии в анамнезе и КН. В тече-

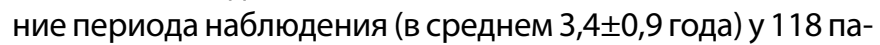
циентов наблюдались эпизоды гипогликемии, из них 43\% получали в качестве сахароснижающей терапии производные сульфонилмочевины, 34\% - метформин, 11\% - инсулин. Эпизоды гипогликемии у больных СД2, включенных в исследование, были идентифицированы с помощью базы данных HIRAS, где фиксировались случаи госпитализации, обусловленные гипогликемическими состояниями.

В результате наблюдения обнаружено, что у больных, у которых имели место эпизоды гипогликемии, потребовавшие госпитализации, по сравнению с теми, у кого подобных эпизодов не зафиксировано, деменция развивалась статистически значимо чаще (6,83 человеко-лет против 18,26, $\mathrm{p}=0,0139)$, а вот различия в частоте развития недементных КН у больных с эпизодами гипогликемии в сравнении с пациентами без них были не столь выражены и статистически незначимы (0,49 человеко-лет против 2,61 соответственно, $p=0,1106)$. После коррекции на данные анамнеза и принимаемые лекарственные препараты отмечено, что у больных, имевших $\geq 1$ эпизода гипогликемии, потребовавших госпитализации, за период наблюдения, риск деменции был повышен в 2,7 раза 
(ОШ=2,689, 95\% ДИ 1,080-6,694, p=0,0335). Выявлена также статистически значимая линейная зависимость между риском развития деменции и количеством фиксировавшихся в исследовании эпизодов гипогликемии $(p=0,0286)$. Полученные данные позволили авторам сделать вывод о том, что у больных СД2 в возрасте старше 60 лет при наличии эпизодов гипогликемии, потребовавших госпитализации, деменция развивается чаще. Наличие подобных эпизодов статистически значимо ассоциировано с более чем двукратным повышением риска деменции, даже после поправки на наличие других факторов риска, причем увеличение риска деменции линейно связано с количеством гипогликемических событий.

В цитируемом выше проспективном наблюдательном исследовании Feinkohl и соавт. [37] к концу периода наблюдения (4 года) в группе пожилых больных СД2 с тяжелыми гипогликемиями в анамнезе отмечалось более быстрое когнитивное снижение; так, специальный интегральный показатель «g» в этой группе составил -0,26 (95\% ДИ -0,49--0,04) против 0,04 (95\%ДИ: -0,04-0,11) в группе пациентов с СД без эпизодов гипогликемий $(p=0,008)$ [33].

Однако имеются и исследования, в которых взаимосвязь эпизодов гипогликемий с развитием и прогрессированием КН, в том числе деменции, была не столь очевидна. Так, Bruce и соавт. [33] в течение длительного времени наблюдали больных из Fremantle Diabetes Study (FDS), в котором принимали участие 1426 пациентов с СД в возрасте $\geq 70$ лет (1993-1996). В 2001 г. (через $7,6 \pm 1,0$ года после исходного визита в исследовании FDS) у 302 больных в возрасте $\geq 70$ лет (средний возраст 75,7士4,6 года) проведено тестирование когнитивных функций. При этом у 9,3\% больных была выявлена деменция (в том числе у 16 больных вероятная болезнь Альцгеймера) и у 19,9\% - недементные КР. Из оставшихся 246 больных с нормальными когнитивными функциями (согласно результатам проводившихся когнитивных тестов) через 18 мес повторное когнитивное тестирование выполнено у 205 человек (средний возраст 76,0 44,6 года, СД2 - в 99,0\% случаев, 27,5\% из них находились на инсулинотерапии, 45,0\% принимали производные сульфонилмочевины, у 46,4\% $\mathrm{HbA}_{1 с}$ был $\left.\leq 7,0 \%\right)$. Оценка когнитивных функций была выполнена с помощью тестов Mini-Mental State Examination (MMSE) и опросника информанта (родственника или лица, осуществляющего уход за пациентом) о когнитивном снижении у пожилых (the Informant Questionnaire for Cognitive Decline in the Elderly, IQCODE). Если по шкале MMSE количество баллов было меньше 28, или по шкале IQCODE $\geq 3,31$, или имелись субъективные КН (жалобы на снижение памяти), осуществлялись дополнительное тестирование когнитивных функций и клиническая оценка с целью диагностики деменции в соответствии с критериями Диагностического и статистического руководства по психическим расстройствам (Diagnosticand Statistical Manual of Mental Disorders, Fourth Edition (DSM-IV)). Тяжесть деменции была определена в соответствии с клинической рейтинговой шкалой деменции (Clinical Dementia Ratingscale, (DR). Через 18 мес прогрессирование КН фиксировалось в том случае, если у больных без исходных КН развивалась деменция/недементные КН или если недементные КН прогрессировали до стадии деменции.
Учет эпизодов предшествующей гипогликемии был проведен ретроспективно, на основании либо самоотчетов пациентов (наличие в анамнезе эпизодов тяжелой гипогликемии, требующих посторонней помощи); либо эпизодов, подтвержденных врачом на основании специального опросника (включающего вопросы об истории, частоте, симптомах и тяжести гипогликемии) и измерения уровня глюкозы крови (гипогликемия диагностировалась при уровне гликемии <3,5 ммоль/л), при этом подтвержденные врачом эпизоды гипогликемии были подразделены на 3 категории: любые эпизоды гипогликемии, тяжелая гипогликемия (эпизоды, требующие посторонней помощи) и нейрогликопения (эпизоды гипогликемии с соответствующими симптомами); либо эпизодов гипогликемии, потребовавших скорой помощи, или посещения учреждений неотложной помощи, или госпитализации, и зафиксированные в базе данных Western Australia Data Linkage System (WADLS) с января 1999 г. по июнь 2006 г. включительно.

Об эпизодах тяжелой гипогликемии (требующей госпитализации) в анамнезе сообщили 7,2\% участников, давность которых в среднем составляла 1,0 $(1,0-6,5)$ лет до оценки когнитивных функций. Подтвержденные врачом эпизоды любой гипогликемии встречались в 39,5\% случаев, тяжелая гипогликемия - в 7,0\% и нейрогликопении - в 8,0\% случаев. Эпизоды гипогликемии, потребовавшие врачебной помощи и зафиксированные в базе данных WADLS, имели место в 3,6\% случаев, в среднем за 1,7 (0,3-4,0) лет до оценки когнитивных функций.

С целью исследования взаимосвязи между КН или деменцией, с одной стороны, и наличием эпизодов гипогликемии за период наблюдения, с другой, авторы первоначально провели поперечный (кросс-секционный) анализ в общей когорте из 302 больных, с определением наличия эпизодов гипогликемий в анамнезе у участников, которых разделили на 4 подгруппы: отсутствие $\mathrm{KH}$, наличие недементных КН, деменция, недементные $\mathrm{KH}+$ деменция.

В подгруппе пациентов с деменцией $(\mathrm{n}=28)$ статистически значимых взаимосвязей ее наличия с эпизодами гипогликемии выявлено не было, возможно, из-за малого количества наблюдений. Однако в подгруппе недементных КН были обнаружены статистически значимые ассоциации с наличием эпизодов тяжелой гипогликемии, согласно данным самоотчета пациентов (OP 2,96; 95\% ДИ 1,05-8,33; $p=0,040$ ), нейрогликопении (OP 5,10; 95\% ДИ 1,46-17,87; $p=0,011)$, а также с наличием эпизодов гипогликемии, потребовавших скорой помощи, или посещения учреждений неотложной помощи, или госпитализации, и зафиксированные в базе данных Western (ОР 9,65; 95\% ДИ 1,65-56,60; $p=0,012$ ). В объединенной подгруппе (недементные КН + деменция) также была выявлена статистически значимая взаимосвязь с эпизодами тяжелой гипогликемии, верифицированной лечащими врачами (ОР 4,83; 95\% ДИ: 1,29-18,13; p=0,020), нейрогликопении (ОР 5,04; 95\% ДИ 1,53-16,57; p=0,008) и с тяжелыми гипогликемиями, зафиксированными в базе данных Western (OР 6,44; 95\% ДИ 1,22-34,14; $\mathrm{p}=0,029)$.

Далее авторами была сформирована когорта, включившая 205 больных (из 302 ранее включенных), у которых первое тестирование не выявило деменции и недементных КН, с проведением повторного тестирования 
когнитивных функций в среднем через 1,6 года наблюдения (медиана 1,6 (1,4-1,8) лет). При этом из 205 больных у 33 (16,1\%) констатировано ухудшение когнитивных функций (у 4 больных развилась деменция, а у 29 - недементные КН), однако статистически значимых различий по частоте эпизодов тяжелой гипогликемии между больными с наличием и отсутствием ухудшения когнитивных функций выявлено не было.

Третий субанализ, выполненный авторами, касался когорты 27 из 302 больных (8,9\%), у которых было зарегистрировано 40 эпизодов тяжелой гипогликемии между первым когнитивным тестированием и последним визи-

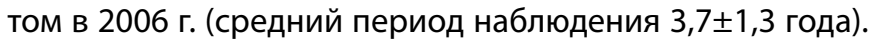
У пациентов с наличием эпизодов тяжелых гипогликемий частота деменции составила 33,3\%, а у пациентов без подобных эпизодов - 6,9\% (различия между группами статистически значимы, $p<0,001)$. Однако данный анализ не позволяет сделать выводы о причинно-следственных связях между деменцией и гипогликемией [33].

\section{Ретроспективные исследования}

Целью ретроспективного исследования Whitmer и соавт. [38], в который включены данные 16667 по-

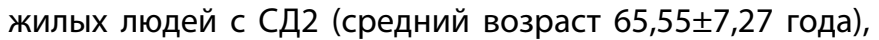
было определение взаимосвязи между тяжелыми гипогликемиями (потребовавшими неотложной помощи или госпитализации и зафиксированными в базе данных медицинских учреждений) с повышенным риском развития деменции в популяции пожилых людей. Продолжительность СД у участников исследования в среднем

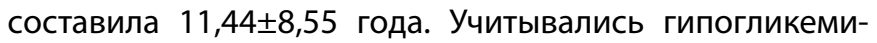
ческие эпизоды, зафиксированные в определенный период времени (с 1 января 1980 г. по 31 декабря 2002 г.), до оценки когнитивного статуса. Тяжелые гипогликемии были зафиксированы у 1465 пациентов, из них 68,5\% имели 1 эпизод, 18\% - 2 эпизода и 13,5\% - $\geq 3$ эпизодов гипогликемии, 37,75\% больных с тяжелыми гипогликемиями в анамнезе находились на инсулинотерапии.

В результате исследования было выявлено, что у больных с эпизодами тяжелых гипогликемий скорректированные по возрасту показатели заболеваемости деменцией были выше. Так, у пациентов с $\geq 1$ эпизодом гипогликемии показатель заболеваемости составил 566,82 случаев (95\% ДИ 496,52-637,48) на 10000 человеко-лет против 327,6 случаев (95\% ДИ 311,02-343,18) на 10000 человеко-лет у пациентов без гипогликемических эпизодов. Риск развития деменции у пациентов с $\geq 1$ эпизодом гипогликемии по сравнению с пациентами без подобных эпизодов составил 2,39 (95\% ДИ 1,72-3,01). При этом наибольшее увеличение риска отмечено у больных с $\geq 3$ эпизодами гипогликемии. Так, в этой группе риск развития деменции был повышен на 94\% (ОР 2,60; 95\% ДИ 1,78-3,79), в то время как у пациентов с 2 или 1 эпизодом гипогликемии риск деменции в течение 27 лет наблюдения был повышен на $80 \%$ (ОР 1,80; 95\% ДИ 1,37-2,36) и 26\% (ОР 1,26; $95 \%$ ДИ 1,10-1,49) соответственно по сравнению с больными без эпизодов гипогликемии [38]. Полученные в результате исследования данные свидетельствуют о наличии взаимосвязи между наличием эпизодов тяжелой гипогликемии у пожилых пациентов с СД2 и повышенным риском развития деменции.
В ретроспективное исследование Mehta и соавт. [39] были включены 55033 пациентов в возрасте >65 лет с СД2 без деменции. В течение периода наблюдения (2003-2012 гг.) 5,7\% (n=3018) имели по крайней мере один эпизод гипогликемии, 0,8\% (n=503) - 2 эпизода, 0,5\% (n=314) - >2 эпизодов гипогликемии. При этом $61,5 \%$ пациентов с СД2 находились на инсулинотерапии (монотерапия или комбинация с пероральными сахароснижающими препаратами). Среднее время наблюдения составило 3,8 (1,8-6,3) лет. Случаи эпизодов гипогликемии изучались на основании баз данных CPRD и HES, фиксировавших эпизоды амбулаторной, неотложной и стационарной помощи (то есть гипогликемии следует рассматривать как тяжелые) лицам, включенным в исследование при развитии гипогликемических состояний.

Заболеваемость деменцией составила 12,7 на 1000 человеко-лет, при этом заболеваемость деменцией у больных с эпизодами гипогликемии была 19,8 на 1000 человеко-лет, ау пациентов без эпизодов гипогликемии -12,5 на 1000 человеко-лет. В среднем время от первого эпизода гипогликемии до развития деменции составило $1,8(0,8-3,8)$ лет. У больных по крайней мере с одним эпизодом гипогликемии риск развития деменции был повышен на 27\% (ОШ 1,27; 95\% ДИ 1,06-1,51) по сравнению с пациентами без гипогликемических эпизодов. С увеличением количества эпизодов гипогликемии риск деменции увеличивался. Так, наличие одного эпизода гипогликемии соответствовало повышению риска развития деменции на 26\% (ОР 1,26; 95\% ДИ 1,03-1,54), а наличие $\geq 2$ эпизодов увеличивало риск на 50\% (ОР 1,50; 95\% ДИ 1,09-2,08) по сравнению с пациентами без гипогликемии. На основании полученных данных исследователями был сделан вывод о том, что тяжелая (потребовавшая посторонней помощи) гипогликемия связана с более высоким риском развития деменции у пожилых пациентов с СД2.

\section{ПАТОФИЗИОЛОГИЧЕСКИЕ МЕХАНИЗМЫ, ОБУСЛОВЛИВАЮЩИЕ ПОВЫШЕННЫЙ РИСК РАЗВИТИЯ/ПРОГРЕССИРОВАНИЯ КОГНИТИВНЫХ НАРУШЕНИЙ У БОЛЬНЫХ СД2}

Выделяют ряд патофизиологических механизмов, которые могут привести к повышенному риску развития/ прогрессирования КН у пожилых больных СД2 с гипогликемией $[11,40]$. Во-первых, гипогликемия может привести к гибели нейрональных клеток, что особенно важно у лиц данной возрастной группы, так как для людей пожилого и старческого возраста характерна ограниченная нейрональная пластичность. Во-вторых, гипогликемия увеличивает агрегацию тромбоцитов и образование фибриногена и может привести к микротромбозам. И, наконец, гипогликемия может обусловливать повреждение рецепторов в зонах головного мозга, отвечающих за обучение и память.

Так, с точки зрения патогенетических основ, потенцирующих развитие деменции на фоне гипогликемии, в первую очередь следует рассмотреть механизмы повреждения и гибели нейронов, которые запускаются при падении концентрации глюкозы в крови.

Одним из наиболее ранних неблагоприятных проявлений гипогликемии на уровне центральной нервной системы служит повреждение митохондрий, что, в свою 
очередь, ведет к дефициту аденозинтрифосфата (АТФ), а также индуцирует срыв электролитного гомеостаза [41]. При критическом снижении уровня глюкозы крови создаются условия для выхода из нейронов ионов калия и поступления в их цитоплазму ионов кальция. Повышение уровня внутриклеточного кальция способствует росту проницаемости внутренней мембраны митохондрий, на фоне чего в данные органеллы начинают проникать молекулы с массой менее 1500 Да. Это приводит к набуханию и повреждению митохондрий, в их цитозоль высвобождается цитохром С, который, как известно [42], в норме участвует в инициировании апоптоза посредством активации каспаз. На роль апоптоза в гибели нейронов на фоне гипогликемии указывают результаты клинических и экспериментальных работ [42, 43]. В частности, в период восстановления после перенесенного гипогликемического состояния отмечаются повышение концентрации внутриклеточного цитохрома С в ткани головного мозга, перераспределение данного протеина в гиппокампе в зоне CA1 (cornu ammonis 1) и в области зубчатой извилины и увеличение экспрессии проапоптотического белка Вах В поверхностных слоях неокортекса [42]. В гиппокампе на фоне гипогликемии также наблюдаются существенное повышение активности каспазы-3 и кальпаин-индуцированное разрушение белка фодрина, который является мембран-ассоциированным протеином цитоскелета и расщепляется каспазами в ходе апоптоза [43].

В исследованиях на лабораторных животных показано влияние гипогликемии и на содержание в структурах головного мозга нейротрансмиттеров. Нарастание концентрации внутриклеточного кальция способствует высвобождению производных аминокислот - аспартата и глатумата из пресинаптических окончаний $[41,44]$. Наиболее выраженно повышается уровень аспартата, его содержание в нейронах увеличивается в 4 раза, а в экстрацеллюлярной среде - в 16 раз [41]. Следует указать, что особенно существенно концентрация аспартата возрастает в окончаниях возбуждающих афферентных нейронов, однако его содержание также повышается и в нейронах, функционирование которых опосредуется гамма-аминомасляной кислотой (ГАМК). Возбуждающие аминокислоты вызывают гибель нейронов, воздействуя на N-метил-D-аспартатные рецепторы (NMDA-рецепторы) [41, 45]. Как считается, наиболее уязвимыми с этой точки зрения являются клеточные элементы зубчатой извилины гиппокампа, поскольку, с одной стороны, нейроны данной области имеют богатое представительство NMDA-рецепторов, а с другой стороны, располагаются вблизи структур головного мозга, содержащих ликвор, что играет важную роль, так как при гипогликемии в цереброспинальной жидкости обнаруживается высокая концентрация аспартата [45]. Активация NMDA-рецепторов сопровождается рядом неблагоприятных событий. Во-первых, стимулируется поступление ионов кальция внутрь нейронов, которое может провоцировать гибель последних через указанные выше механизмы. Во-вторых, индуцируется массивная продукция супероксида, также ведущая к разрушению нейронов. Образование супероксида на фоне стимуляции NMDA-рецепторов связывают как с работой цитоплазматической НАДФН-оксидазы, так и с деятельностью митохондрий [46].
Еще одной мишенью гипогликемических состояний служит биосинтетический аппарат нейронов. В частности, обнаружено, что на фоне дефицита глюкозы в крови происходит снижение сборки матричной РНК нейропептида Y и проопиомеланокортина почти на 50\% [47]. В дополнение к этому гипогликемия ассоциируется со снижением электрической активности головного мозга по данным электроэнцефалографии и почти полной блокадой биосинтеза белка в соответствующих зонах центральной нервной системы. К ним, например, относятся слои III-VI коры головного мозга, гиппокамп (пирамидные нейроны в зонах СА3, СА4, гранулярные нейроны зубчатой извилины) и каудальная область скорлупы [41]. Следует отметить, что, по данным исследований, после эпизода гипогликемии и восстановления нормального уровня глюкозы в крови в отдельных участках головного мозга (зубчатая извилина, мелкие нейроны дорсолатеральной части каудальной порции скорлупы) биосинтетическая активность нередко не восстанавливается, свидетельствуя о гибели здесь нервных клеток, в других же зонах (область СА1, нейроны средних размеров каудальной части скорлупы) синтез белка восстанавливается лишь частично, указывая на необратимое повреждение нейронов [41].

На фоне дефицита глюкозы также возникают нарушения обмена дофамина, который, в числе прочего, участвует в когнитивных процессах. В частности, в экспериментальных исследованиях было продемонстрировано, что на фоне гипогликемии в гиппокампе значительно снижается уровень самого дофамина и его метаболита гомованилиновой кислоты, и повышается экспрессия генов, кодирующих рецепторы к этому нейромедиатору [48].

Гипогликемия влияет на образование нервной ткани. Как показано в работах на грызунах, в течение первых недель после тяжелой гипогликемии наблюдается транзиторное усиление пролиферации прогениторных клеток в центральной нервной системе, сменяющееся затем падением их способности к делению ниже нормального уровня [49]. Считается, что снижение нейрогенеза связано с недостаточным высвобождением ионов цинка из пресинаптических окончаний, возникающим ввиду дегенерации нервных волокон. В целом баланс ионов цинка играет одну из важнейших ролей в поддержании жизнеспособности нейронов, и повышение его уровня, как и недостаток, может оказывать неблагоприятные эффекты на нервную ткань. Так, в экспериментальных моделях было установлено, что на фоне восстановления уровня глюкозы после периода гипогликемии триггером повреждения нейронов являются ионы цинка, высвобождающиеся под действием оксида азота [50]. Точные механизмы нейротоксического действия цинка до конца не изучены. Как предполагается, данные ионы могут воздействовать напрямую на нейроны, способны стимулировать агрегацию белков (например, при болезни Альцгеймера и хорее Гентингтона) и активировать микроглию [41, 50], структурные элементы которой вызывают гибель нейронов посредством выделения протеаз, активных форм кислорода и провоспалительных факторов. Помимо этого, цинк подавляет захват астроцитами глутамата через индукцию поли(АДФ-рибоза)-полимеразы-1 [англ. poly (ADP-ribose) polymerase-1, или PARP-1]. В постсинаптических нейронах цинк также активирует 
НАДФ-Н-оксидазу и PARP-1, что ведет к оксидативному стрессу, повреждению ДНК, снижению содержания никотинамидадениндинуклеотида и АТФ и, в конечном счете, к гибели нейронов.

Необходимо также указать на потенциальное влияние изменения кислотно-щелочного состояния на работу нейронов. Согласно литературным данным, при гипогликемии в центральной нервной системе наблюдается повышение $\mathrm{pH}$, то есть «защелачивание» среды [45]. Это обусловлено как дефицитом лактата, который в данных условиях может расходоваться как энергетический субстрат, так и избыточным образованием аммония в силу катаболизма аминокислот.

Помимо непосредственного влияния гипогликемии на структурно-функциональную целостность нервной ткани, необходимо принимать во внимание сопутствующую активацию симпатической нервной системы [51], несущую за собой целый каскад патофизиологических событий, способных негативным образом сказываться на работе нейронов, вызывать ишемию головного мозга и в том числе предрасполагать к нарушению когнитивного функционирования, а в дальнейшем вести и к деменции. С этой точки зрения наиболее важными последствиями гиперсимпатикотонии являются стимуляция агрегации тромбоцитов, ускорение образования фибриногена, нарушение баланса фибринолиза, провоцирование провоспалительного и прокоагуляционного состояний и возникновение эндотелиальной дисфункции.

\section{РИСК РАЗВИТИЯ ЭПИЗОДОВ ГИПОГЛИКЕМИИ У БОЛЬНЫХ СД2 И ДЕМЕНЦИЕЙ}

Известно, что около $10 \%$ лиц с деменцией имеют СД [52], и повышенный риск развития гипогликемии у таких пациентов является серьезной проблемой, которая заслуживает отдельного рассмотрения. Пациенты с деменцией как в силу преклонного возраста, так и в связи с наличием тяжелых КН зачастую не могут адекватно выполнять предписания лечащего врача, а усугубляют положение проблемы с питанием (синдром мальнутриции или недостаточности питания), которые также часто имеют место у этой категории больных [30]. Поэтому у гериатрических пациентов особое внимание уделяется безопасности сахароснижающих препаратов, прежде всего такой НПР при их применении, как гипогликемия. Профилактика гипогликемии является одной из целей лечения СД у этой категории больных [26]. В литературе имеется ряд исследований, посвященных данному вопросу.

\section{Метаанализы}

В уже упоминавшемся ранее метаанализе Mattishentand, Y. Loke [34], 5 из 9 проспективных и ретроспективных исследований, включенных в метаанализ, были отобраны для изучения деменции как предиктора развития тяжелых гипогликемических состояний. Количество больных СД2 в исследованиях варьировало от 302 до 497 900, средняя продолжительность заболевания - от 8 до 11,8 года. Средний возраст участников в 2 исследованиях составлял 74 и 76 лет, в одном из исследований он охарактеризован как $\geq 50$ лет, во втором $\geq 55$ лет, в третьем - $\geq 65$ лет. Количество больных с нали- чием деменции на визите включения колебалось от $2 \%$ до 15,7\%, пациентов с КН - от 6,4\% до 19,9\%. На инсулинотерапии находились от 16,3\% до 49,9\% больных, включенных в исследования. Период наблюдения в разных исследованиях составлял от 18 мес до 12 лет. В результате проведенного анализа исследователи пришли к выводу о том, что пациенты с деменцией обладают повышенным риском развития гипогликемии (ОШ 1,61; 95\% ДИ $1,25-2,06 ; p=0,0002)$.

\section{Проспективные исследования}

В цитируемом ранее исследовании Bruce и соавт. [33], которые в течение 18 мес наблюдали 205 пациентов с СД2 (99,0\%), обнаружено, что тяжелая гипогликемия (выявленная с помощью анкетирования пациента, либо установленная врачом при опросе/осмотре, либо зафиксированная в специальной базе данных) чаще имела место у пациентов с уже имеющимися КН $(6,7 \%)$ или деменцией (17,9\%), чем у лиц с нормальным когнитивным статусом (0,9\%).

Пациенты с СД2 и деменцией за время периода наблюдения имели значительно более высокий риск развития тяжелых гипогликемий, закончившихся госпитализацией (ОР 3,02; 95\% ДИ 1,07-8,53; p=0,037). Относительный риск с поправкой на терапию инсулином составил 2,77 (95\% ДИ 1,18-6,46; $p=0,019)$, а с поправкой на неспособность самостоятельно принимать лекарства - 4,19 (95\% ДИ 1,43-12,25; p=0,009). Деменция у пожилых больных была предиктором развития тяжелых гипогликемий, закончившихся госпитализацией (OP 20,26; 95\% ДИ 6,00-68,44; p<0,001), кроме того, у пожилых больных с СД и деменцией предиктором развития тяжелых гипогликемических состояний была терапия инсулином (ОР 14,60; 95\% ДИ 3,49-61,12, p<0,001) [35].

Проспективное когортное субисследование ACCORDMIND исследования ACCORD (Action to Control Cardiovascular Risk in Diabetes) [53] было посвящено изучению влияния КН на риск развития тяжелых гипогликемий у больных СД2. В окончательный анализ было включено 2956 пациентов в возрасте >55 лет (средний возраст 62,49 $\pm 5,82$ года), средняя длительность СД со-

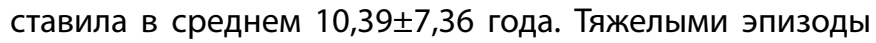
гипогликемии признавались, если требовали любой посторонней помощи или специализированной медицинской помощи, учет велся по результатам самоотчетов пациентов, а также при изучении баз данных медицинских учреждений, фиксировавших случаи госпитализации пациентов с гипогликемическими состояниями. Когнитивные функции оценивали исходно (в течение 45 дней после рандомизации) и через 20 мес с помощью ряда когнитивных тестов (тест замены цифровых символов (Digit Symbol Substitution Test, DSST), тест Рея на слухоречевую память (Rey Auditory Verbal Learning Test, RAVLT), тест Струпа (Stroop test), Краткая шкала оценки психического статуса (Mini-Mental State Examination, MMSE)). Исследование когнитивного статуса осуществлялось после определения уровня гликемии, в том случае, если уровень глюкозы в крови был $\geq 3,3$ ммоль/л.

В последующем за период наблюдения (в среднем 3,25 года) 238 из 2956 пациентов сообщили как минимум об одном эпизоде гипогликемии, требовавшей любой посторонней помощи, из них 73 пациента сообщили о на- 
личии $\geq 2$ эпизодов. При этом 99 больных, ранее не имевших эпизодов гипогликемии, сообщили по крайней мере о 2 эпизодах в течение периода наблюдения. Было обнаружено, что исходное состояние когнитивных функций ассоциировано с риском развития эпизодов тяжелых гипогликемий. Так, исходно более низкий результат теста замены цифровых символов (DSST) на 5 баллов являлся статистически значимым предиктором развития первого эпизода гипогликемии, требовавшего медицинской помощи (ОШ=1,13; 95\% дИ 1,08-1,18). Сходные данные получены и в отношении результатов других когнитивных тестов. Кроме того, в подгруппе пациентов с исходно худшими показателями когнитивных тестов обнаружено, что их ухудшение при повторном тестировании (через 20 мес) статистически значимо коррелирует с риском развития тяжелой гипогликемии. Результаты были сопоставимы в группах интенсивного и стандартного гликемического контроля [53]. Следовательно, проведение ACCORD-MIND позволило выявить, что наличие KH acсоциировано с повышенным риском развития эпизодов тяжелых гипогликемий в будущем.

\section{Исследования поперечного типа}

В исследовании DIMORA (Dlabete MellitO in RsA) [54] участвовали 2258 пациентов с СД2 (средний возраст $83 \pm 7$ лет) из 150 учреждений долговременного ухода. Средняя продолжительность СД у включенных больных составляла $12,6 \pm 8,1$ года. Включенные в исследование пациенты были разделены на группы с наличием $(n=1138)$ и с отсутствием деменции $(n=1120)$. В качестве сахароснижающей терапии использовались пероральные лекарственные средства (чаще всего препараты сульфонилмочевины и метформин) и инсулинотерапия. Препараты инсулина получали 35\% больных с деменцией, терапию пероральными сахароснижающими препаратами - 47\%, комбинированную терапию (инсулин + пероральные сахароснижающие препараты) - 5\% (33\%, 49\% и 8\% у больных без деменции соответственно). Гипогликемические состояния фиксировались при опросе или осмотре участников врачами или средним медицинским персоналом, проводившим ежедневный мониторинг гликемии. Период наблюдения продолжался 24 мес.

В результате исследования было отмечено, что тяжелая гипогликемия (<2,8 ммоль/л и требовавшая посторонней помощи) чаще развивалась у пациентов с деменцией (18\%) по сравнению с пациентами без деменции (8\%). Пациенты с деменцией имели скорректированный риск развития тяжелого гипогликемического события, в 2 раза превышающий таковой для пациентов без деменции (ОШ 2,029; 95\% ДИ 1,325-3,108). Авторы сделали вывод о том, что у пожилых пациентов с деменцией, проживающих в учреждениях долговременного ухода, риск развития тяжелой гипогликемии значительно выше, чем у пациентов без деменции. Также в этом исследовании была установлена взаимосвязь между конкретными сахароснижающими препаратами и риском деменции, что будет рассмотрено ниже.

Ретроспективные исследования

В исследовании Prinz и соавт. [55] анализировали данные 6770 больных СД2 и деменцией (средний возраст
79,9 года) и 209162 пациентов с СД2 без деменции (средний возраст 70,1 года). Наибольшее количество больных с деменцией $(13,1 \%)$ было зафиксировано в возрастной группе $\geq 90$ лет. На инсулинотерапии находились 59,3\% пациентов с СД2 и деменцией, производные сульфонилмочевины принимали 13,1\%, метформин - 28,55\% больных. В результате было выявлено, что риск развития тяжелой гипогликемии у больных СД2 и деменцией на $30 \%$ выше $(7,75 \pm 0,29$ на 100 человеко-лет), чем у пациентов

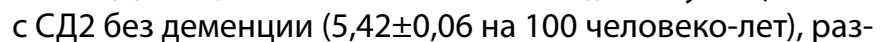
личия между группами статистически значимы $(p<0,001)$, а риск развития гипогликемической комы у больных СД2

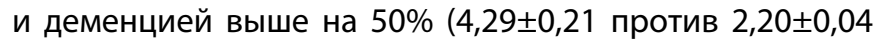
у пациентов с СД2 без деменции, $\mathrm{p}<0,001)$.

В исследовании Feil и соавт. [56], проанализировавшем данные 479900 больных СД2 в возрасте $\geq 65$ лет, изучался риск развития гипогликемии у больных с деменцией или недементными КН. Распространенность деменции и когнитивных нарушений в этом исследовании составила 13,1\% среди больных в возрасте от 65 до 74 лет и 24,2\% - у пациентов в возрасте 75 лет и старше. Наибольшая распространенность деменции была у больных, находящихся в учреждениях долговременного ухода (45,3\%). Количество пациентов на инсулинотерапии в группе больных СД2 с деменцией или недементными КН составило 30\%, у пациентов с СД2 и нормальным когнитивным статусом - 24\%. Авторы обнаружили, что частота развития эпизодов гипогликемии была выше как у больных с деменцией (14,1\%), так и у пациентов с КН (10,4\%) по сравнению с больными без KН (6,3\%). В целом частота развития эпизодов гипогликемии у больных СД2, проживающих в учреждениях долговременного ухода, составляла 20,4\%, в подгруппе пациентов с СД2 и деменцией - 22,2\%, в подгруппе больных СД2 и недементными КН - 18,9\%. Был выявлен статистически значимо более высокий риск развития эпизодов гипогликемии как у больных деменцией (скорректированное ОШ=1,58; 95\% ДИ 1,53-1,62), так и у пациентов с недементными КН (скорректированное ОШ=1,13; 95\% ДИ 1,08-1,18).

\section{САХАРОСНИЖАЮЩИЕ ЛЕКАРСТВЕННЫЕ СРЕДСТВА И РИСК РАЗВИТИЯ ГИПОГЛИКЕМИИ У БОЛЬНЫХ СД С КОГНИТИВНЫМИ НАРУШЕНИЯМИ/ДЕМЕНЦИЕЙ}

Влияние разных сахароснижающих препаратов на риск развития эпизодов гипогликемии у больных СД и деменцией/недементными КН оценивалось в ряде цитируемых выше исследований $[54,55]$. В исследованиях, сообщавших о связи между лечением СД и когнитивными исходами, использовались различные сахароснижающие препараты, разные режимы интенсивности противодиабетической терапии в разных по объему выборках, продолжительность периода наблюдения также существенно различалась в разных исследованиях.

Так, в поперечном исследовании DIMORA [54], дизайн которого подробно описан выше, установлено, что у пациентов с СД и деменцией тяжелая гипогликемия развивалась примерно в 8,8 раза чаще при лечении производными сульфонилмочевины (ОШ 8,805; 95\% ДИ 4,260-18,201; p<0,001) и в 6,6 раза чаще - при комбинированном лечении метформин + препараты 
сульфонилмочевины (ОШ 6,639; 95\% ДИ 3,273-14,710; $\mathrm{p}=0,001)$. Терапия препаратами инсулина короткого и пролонгированного действия была статистически значимо ассоциирована с развитием эпизодов тяжелой гипогликемии (ОШ 0,333; 95\% ДИ 0,184-0,602; $\mathrm{p}<0,001$ и ОШ 0,248;95\% ДИ 0,070-0,882; $p=0,031$ соответственно). Монотерапия метформином не была ассоциирована с риском развития тяжелой гипогликемии (ОШ 0,678; 95\% ДИ 0,380-1,210; $p=0,189)$. У больных СД2 без деменции статистически значимых ассоциаций между конкретными схемами сахароснижающей терапии и наличием эпизодов тяжелой гипогликемии обнаружено не было. Группы больных СД с наличием/отсутствием деменции были сопоставимы по всем исходным характеристикам, в том числе и по видам сахароснижающей терапии (инсулин, пероральные препараты, инсулин+пероральные препараты). В результате авторы сделали вывод о том, что у пожилых пациентов с деменцией, проживающих в учреждениях долговременного ухода, следует с осторожностью использовать производные сульфонилмочевины и препараты инсулина, особенно короткодействующие [54].

Prinz и соавт. [55] в своем ретроспективном исследовании обнаружили, что у больных СД2 и деменцией инсулинотерапия (в том числе в сравнении с другими сахароснижающими препаратами) сопровождалась статистически значимо большим риском развития тяжелой гипогликемии (состояние, требующее посторонней помощи) и гипогликемической комы в сравнении с пациентами с СД2 без деменции (14,8 0 ,6 против $10,4 \pm 0,2$ случа-

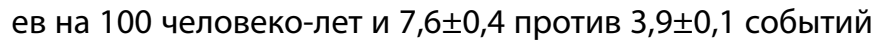
на 100 человеко-лет).В ретроспективном исследовании D.G. Feil et al. [56] также выявлено, что из всех больных СД2, получающих инсулин, эпизоды гипогликемии (диагностированные при амбулаторном посещении, а также послужившие причиной госпитализации или обращения в отделение неотложной помощи) чаще отмечаются в подгруппе больных с наличием деменции (26,5\%) и в подгруппе пациентов с недементными КН (19,5\%), чем в подгруппе больных без КН (14,4\%).

Учитывая изложенное, становится очевидным, что взаимоотношения между гипогликемией и дементными/недементными КР у лиц пожилого и старческого возраста являются двунаправленными: с одной стороны, тяжелые гипогликемии увеличивают риск развития КН, темпы их прогрессирования и риск деменции, с другой - наличие деменции способствует увеличению риска развития гипогликемии. Пожилые люди с КН в большинстве случаев оказываются неспособными самостоятельно справляться со схемами лечения, предписанными врачами, зачастую не могут своевременно распознать симптомы гипогликемии, а следовательно, и реагировать соответствующим образом, тем самым еще более увеличивая риск гипогликемических состояний. Таким образом, у пациентов старших возрастных групп особое значение имеет не только эффективность сахароснижающей терапии, но и ее безопасность. И можно предположить, что безопасный гипогликемический контроль, способствуя поддержанию стабильного когнитивного статуса больного, в конечном счете будет способствовать профилактике эпизодов гипогликемии.

\section{САХАРОСНИЖАЮЩИЕ ЛЕКАРСТВЕННЫЕ СРЕДСТВА И РИСК РАЗВИТИЯ КН/ДЕМЕНЦИИ}

\section{Метаанализ}

В метаанализ McMilan и соавт. [57] были включены результаты 13 исследований (4 - рандомизированные клинические исследования и 9 - наблюдательные) с количеством участников от 634 до 145928 (72\% >1000 участников, 70\% включенных больных были старше 65 лет), период наблюдения в исследованиях варьировал от 6 мес до 14,7 года (77\% - >3 лет). Критерием включения исследований в метаанализ было наличие у участников СД2, ассоциированного с деменцией или умеренными $\mathrm{KH}$. В качестве сахароснижающей терапии наиболее часто использовались инсулин (от 5,2\% до 25\%), производные сульфонилмочевины (от 25\% до 43\%), метформин (от $13 \%$ до 50\%) как в качестве монотерапии, так и в составе комбинированной сахароснижающей терапии (производные сульфонилмочевины + метформин - 62\%).

В метаанализе проведено сравнение интенсивной сахароснижающей терапии при использовании различных препаратов со стандартной, с учетом потенциальной связи интенсивной терапии с повышенной частотой эпизодов гипогликемии. Обнаружено, что повышенный риск развития деменции был ассоциирован с инсулинотерапией (ОР 1,87; 95\% ДИ 1,09-3,03) и терапией производными сульфонилмочевины (ОР 1,77; 95\% ДИ 1,04-2,16), но не с терапией метформином (OP 0,82; 95\% ДИ 0,61-1,26).

Влияние гипогликемии на когнитивные функции изучалось в 7 исследованиях [33, 35, 36, 38, 39, 58, 59], включенных в метаанализ, в 3 из них $[35,36,38]$ оценивалось влияние на когнитивный статус эпизодов тяжелых гипогликемий (требовавших госпитализации). Обнаружено, что у больных с тяжелыми гипогликемиями риск развития деменции был увеличен почти вдвое (ОР 1,77; 95\% ДИ 1,35-2,33), причем конкретная схема сахароснижающей терапии оказывала существенное влияние на риск деменции. Так, инсулинотерапия была ассоциирована с увеличением риска деменции на 21\% по сравнению с другими видами сахароснижающей терапии или плацебо (ОР 1,21; 95\% ДИ 1,06-1,39). В целом по данным метаанализа использование производных сульфонилмочевины не сопровождалось статистически значимым увеличением риска развития деменции по сравнению с другими видами сахароснижающей терапии (OP 0,96; 95\% ДИ 0,69-1,34). Однако следует отметить, что в одном из исследований, не включенных в метаанализ, использование препаратов сульфонилмочевины было статистически значимо ассоциировано с повышенным риском развития деменции в сравнении с терапией метформином (ОШ 1,24; 95\% ДИ 1,10-1,40) [60]. Риск развития деменции на фоне лечения метформином (оценивался в 3 исследованиях, включенных в метаанализ $[61,62,63])$ статистически значимо не повышался (ОР 1,08; 95\% ДИ 0,49-2,36). Представляет интерес тот факт, что в одном из исследований (T.P. Ng et al. [64]) был проведен специальный анализ взаимосвязи между терапией метформином и деменцией с поправкой на длительность СД и было выявлено статистически значимое снижение риска развития КН у больных, принимающих метформин, по сравнению с пациентами, получающими другие саха- 
роснижающие препараты (ОР 0,49; 95\% ДИ 0,25-0,95). Более того, выявлено, что длительный прием метформина (более 6 лет) ассоциирован с еще большим снижением риска КН: у пациентов, принимающих метформин длительно, риск КН был ниже на 73\% по сравнению с больными, получающими другие сахароснижающие препараты (ОР 0,27; 95\% ДИ 0,12-0,60).

\section{Исследования поперечного типа}

Исследование Weinstein и соавт. [65], объединившее данные 5 популяционных исследований (Offspring cohort of the Framingham Heart Study (FHS), Rotterdam Study (RS), Atherosclerosis Risk in Communities (ARIC) Study, Aging Gene - Environment Susceptibility-Reykjavik Study (AGES), Sacramento Area Latino Studyon Aging (SALSA)), ставило целью изучить влияние различных сахароснижающих препаратов на когнитивный статус больных СД и оценить риск развития КН и деменции на фоне сахароснижающей терапии.

B FHS был включен 301 пациент (средний возраст 70,1 55,9 года), средняя продолжительность СД составляла 7,5 4,8 года, у 13,8\% больных исходно диагностирована деменция. B RS наблюдали 608 пациентов (средний возраст 63,6士7,8 года) со средней продолжительностью СД 6,4 2,5 года, деменция была диагностирована у 5,1\% больных. В исследование ARIC было включено 1197 пациентов (средний воз-

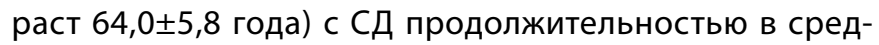

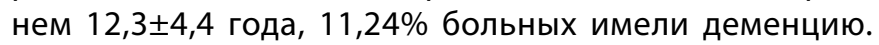
В исследование AGES было включено 623 пациента в возрасте 76,4+5,3 года, страдающих СД в сред-

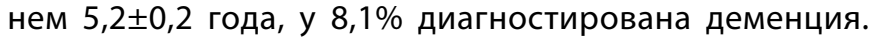

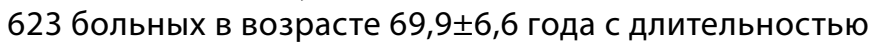

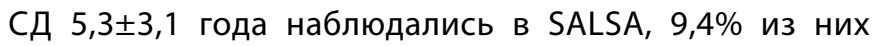
были с деменцией. Наиболее часто используемыми сахароснижающими препаратами в исследованиях были инсулин, производные сульфонилмочевины и метформин. Деменция была диагностирована в соответствии с критериями Диагностического и статистического руководства по психическим расстройствам (Diagnosticand Statistical Manual of Mental Disorders, Revised Third or Fourth Edition (DSM-IIIR, IV)). С помощью широкого спектра когнитивных тестов были оценены интегральный показатель когнитивных функций, память, управляющие функции. Всем пациентам была выполнена магнитно-резонансная томография головного мозга. Продолжительность наблюдения варьировала от 5,2 года (в AGES) до 12,3 года (в ARIC).

В результате исследования Weinstein и соавт. [65] выявлено, что больные, находящиеся на инсулинотерапии, имели повышенный риск развития деменции, равный 50\% (ОР 1,58; 95\% ДИ 1,18-2,12; p=0,002), независимо от наличия депрессии, уровня гликированного гемоглобина и гликемии, по сравнению с пациентами, не получающими инсулин. Терапия производными сульфонилмочевины и метформином не была ассоциирована с повышенным риском развития деменции или недементных КН. Исследователи высказали предположение, что связь инсулинотерапии с риском развития деменции у пожилых больных обусловлена развитием гипогликемических состояний на фоне инсулинотерапии.

\section{ВЛИЯНИЕ МЕТФОРМИНА НА РИСК РАЗВИТИЯ ГИПОГЛИКЕМИИ И КОГНИТИВНЫЙ СТАТУС У ПОЖИЛЫХ ПАЦИЕНТОВ С СД2}

В настоящее время метформин остается препаратом первой линии для лечения СД2 как в отечественных, так и в зарубежных алгоритмах и стандартах медицинской помощи пациентам с СД $[26,66,67]$. Эффективность и безопасность использования метформина как в качестве монотерапии, так и в составе комбинированной терапии подтверждены многими клиническими исследованиями. В свете рассматриваемой проблемы заслуживает особого внимания безопасность использования метформина в отношении развития гипогликемических состояний.

Так, влияние метформина на риск развития гипогликемических состояний рассматривалось в метаанализе Maruthur и соавт. [68] 2016 г., объединившем результаты 204 исследований (81\% - РКИ, остальные - наблюдательные исследования), продолжительностью от 3 мес до 8 лет. Целью метаанализа было оценить сравнительную эффективность и безопасность монотерапии различными сахароснижающими препаратами (тиазолидиндионы, метформин, производные сульфонилмочевины, ингибиторы дипептидилпептидазы 4 типа (иДПП-4), ингибиторы натрий-глюкозного котранспортера 2 (иНГЛТ-2), агонисты рецепторов глюкагоноподобного пептида-1 (АР ГПП-1), и различных комбинаций сахароснижающих препаратов, основанных на метформине) у больных СД2.

Метаанализ показал, что использование метформина в качестве монотерапии или в составе комбинированной терапии с иДПП-4 или иНГЛТ-2 сочетается с меньшим риском гипогликемических эпизодов, в то время как наибольший риск развития эпизодов гипогликемии отмечен на фоне лечения производными сульфонилмочевины как в качестве монотерапии, так и в комбинации с метформином. Так, риск развития тяжелой гипогликемии при монотерапии производными сульфонилмочевины в сравнении с монотерапией метформином был увеличен в 2 раза, а при лечении комбинацией производное сульфонилмочевины + метформин - в 7 раз по сравнению с комбинацией метформин+иНГЛТ-2.

Комбинация метформин+базальный или комбинированный инсулин также увеличивала риск развития гипогликемии в сравнении с комбинацией метформин + АР ГПП-1, в свою очередь, комбинация метформин+комбинированный инсулин была ассоциирована с большим риском развития гипогликемических состояний, чем комбинация метформин+базальный инсулин.

В результате исследования был сделан вывод о том, что высокая эффективность метформина (как в качестве монотерапии, так и составе комбинированной терапии) сочетается с высоким профилем безопасности в отношении риска развития эпизодов гипогликемии [68].

В ретроспективном исследовании Leonard и соавт. [69] сравнивали риски развития эпизодов серьезной (тяжелой) гипогликемии у больных СД2 (потребовавшей неотложной помощи или госпитализации), получающих монотерапию метформином, производными сульфонилмочевины, меглитинидами или тиазолидиндионами. В исследование были включены 925185 человек, средний возраст составил 59,9 года. Первичной конечной точкой исследования было развитие тяжелой 
гипогликемии в течение 180 дней после начала сахароснижающей терапии. Следует отметить, что исследование было ретроспективным, однако для получения более информативных результатов исследователи использовали метод псевдорандомизации.

За период наблюдения было зафиксировано 6406 серьезных гипогликемических событий (частота возникновения составила 28,1 на 1000 человеко-лет). Анализ результатов исследования выявил, что распределение пероральных сахароснижающих препаратов в зависимости от риска развития тяжелых гипогликемий (в сравнении с метформином) было следующим: глибенкламид>глимепирид>глипизид>репаглинид>натеглинид> росиглитазон >пиоглитазон $>$ метформин. Частота эпизодов тяжелой гипогликемии была дозозависимой, увеличиваясь с нарастанием средней суточной дозы всех используемых препаратов. После корректировки на индекс соответствия (вероятность попадания каждого объекта исследования в основную или контрольную группу наблюдения на основании набора его характеристик, этот индекс используется при статистическом методе псевдорандомизации) распределение лекарственных средств по риску развития эпизодов тяжелой гипогликемии изменилось: глибенкламид (ОР 3,95; 95\% ДИ 3,66-4,26) >глимепирид (ОР 3,28; 95\% ДИ 2,98-3,62) >глипизид (OP 2,57; 95\% ДИ 2,38-2,78) >репаглинид (OP 2,03; 95\% ДИ 1,64-2,52) > натеглинид (ОР 1,21; 95\% ДИ 0,88-1,66) =росиглитазон (ОР 0,90; 95\% ДИ 0,75-1,06) = метформин (ОР 1,00; 95\% ДИ 1,00-1,00) >пиоглитазон (ОР 0,80; 95\% ДИ 0,68-0,93).

Низкий риск развития эпизодов гипогликемии на фоне лечения метформином обусловлен механизмом его действия. Современные представления о механизмах действия метформина свидетельствуют о том, что наибольшую активность препарат проявляет в печени, эффективно подавляя процессы продукции глюкозы. Так, индуцированное метформином высокоспецифичное ингибирование комплекса 1 митохондриальной дыхательной цепи сопровождается ингибированием процессов глюконеогенеза и в меньшей степени гликогенолиза, со снижением глюкозы и предшественников (лактат, пируват, глицерол, некоторые аминокислоты), а также противодействием глюконеогенетическому действию глюкагона [70].

В настоящее время в клинической практике используются препараты метформина с разным типом высвобождения: немедленным и пролонгированным.

Сравнение препаратов метформина с разным типом высвобождения в отношении развития эпизодов гипогликемии показало в целом хороший профиль безопасности. Так, в проспективном исследовании Li и соавт. [71] изучались эффективность и безопасность метформина пролонгированного высвобождения (XR) в сравнении с метформином немедленного высвобождения (IR). В исследование были включены 532 пациента, рандомизированные в группу метформина IR (n=267) или метформина XR ( $=265)$. Структура исследования включала 2-недельный период скрининга (набор пациентов, ранее не использовавших сахароснижающую терапию или не принимавших ее в течение месяца и более до начала периода скрининга), 16-недельный период лечения и 2-недельный период последующего наблюдения без лечения. Исследование показало сопоставимую эффективность метформина XR и метформина IR, при этом частота развития гипогликемических состояний при терапии метформином XR была ниже по сравнению с терапией метформином IR и составила 1,10\% и 3,00\% соответственно (95\% ДИ 1,32-5,88\%). В международном рандомизированном двойном слепом исследовании у 568 лиц с СД2 Aggarwal и соавт. [72] проводили сравнение эффективности и безопасности метформина XR и метформина IR, продолжительность периода наблюдения составила 24 нед. Метформин XR, имея преимущество дозирования 1 раз в сутки, в целом продемонстрировал равную метформину IR эффективность. Эпизодов гипогликемии у пациентов, получающих метформин XR, зафиксировано не было, у пациентов, получающих метформин IR, эпизоды гипогликемии наблюдались в $1,1 \%$ случаев.

Рецидивирующие эпизоды гипогликемий, как было подробно рассмотрено выше, являются предикторами развития и прогрессирования когнитивных нарушений у больных СД2 старших возрастных групп. В связи с этим можно ожидать, что сахароснижающие препараты с высоким профилем безопасности в отношении гипогликемии имеют определенные преимущества, поскольку их использование не будет повышать риск развития и прогрессирования КН. В цитируемых выше исследованиях $[57,58]$ терапия метформином, в том числе для интенсивного контроля гликемии, не сопровождается увеличением риска развития деменции, кроме того, длительное использование данного препарата сопровождается снижением темпов прогрессирования КН, то есть можно предполагать наличие у метформина церебропротективного эффекта. В своем метаанализе Campbell и соавт. [73] изучали динамику когнитивного статуса у больных пожилого и старческого возраста с СД2, получавших метформин. Группа сравнения включала пациентов с СД2, не получавших метформин. В метаанализ были включены 14 исследований, большинство из которых были наблюдательными. Размеры выборок варьировали от 114199 до 27 участников, продолжительность наблюдения от 24 недель до 9 лет. Метаанализ показал, что использование метформина у лиц с СД2 было связано с более низким риском развития КН (ОШ 0,55; 95\% ДИ 0,38-0,78; $\mathrm{p=0,0009),} \mathrm{а} \mathrm{также} \mathrm{демен-}$ ции и болезни Альцгеймера (ОР 0,76; 95\% ДИ 0,60-0,97; $\mathrm{p}=0,03)$ по сравнению с лицами с СД2, не получающими метформин.

Результаты нескольких клинических исследований зафиксировали положительный эффект метформина на когнитивные функции при болезни Альцгеймера [64, 74-76].

В литературе имеется несколько публикаций, касающихся изучения механизмов церебропротективных свойств метформина, они включают прямое нейропротективное действие, прежде всего антиоксидантное, снижение активности ацетилхолинэстеразы, которая ответственна за деградацию ацетилхолина, нейротрансмиттера, играющего важную роль в процессах обучения и памяти [71, 77, 78]. Помимо этого, при болезни Альцгеймера имеет значение способность метформина снижать активность белка $\beta$-секретазы- 1 , что обуславливает уменьшение содержания продуктов расщепления белка-предшественника $\beta$-амилоида и продукцию $\beta$-амилоида [64, 74-76]. 


\section{ЗАКЛЮЧЕНИЕ}

СД является общепризнанным фактором риска КН и деменции. При этом и неудовлетворительный гликемический контроль, и рецидивирующие эпизоды тяжелой гипогликемии ассоциированы со снижением когнитивных функций у пожилых людей с СД2, о чем сообщается в многочисленных исследованиях. С другой стороны, пациенты с KР/деменцией оказываются наиболее подверженными риску развития гипогликемических состояний.

Очевидно, что существующая ассоциативная связь между тяжелой гипогликемией и деменцией весьма сложна и носит дуалистичный характер. В настоящее время нет окончательной определенности относительно причинно-следственных связей, что, безусловно, требует дальнейшего изучения вопроса.

Известно, что лечение СД2 у больных пожилого и старческого возраста, часто сочетающегося с недементными КН, а тем более деменцией - сложная задача, требующая учета множества факторов и рисков, в том числе и безопасного профиля переносимости лекарственных средств. Целесообразно применение у этих больных противодиабетических препаратов с низким риском гипогликемий, таких как метформин, представители групп иДПП-4, иНГЛТ-2, АР ГПП-1, а также их рациональных комбинаций. При этом используемый (-ые) сахароснижающий (-ие) препарат (-ы) не должны создавать или усиливать имеющиеся риски развития НПР, а также оказывать отрицательное влияние на сопутствующую патологию.

\section{ДОПОЛНИТЕЛЬНАЯ ИНФОРМАЦИЯ}

Конфликт интересов. Публикация статьи поддержана компанией «Мерк», что никоим образом не повлияло на собственное мнение авторов.

Участие авторов. Остроумова О.Д. - разработка дизайна, набор материала, анализ и интерпретация результатов, написание текста; Суркова Е.В. - разработка дизайна, набор материала, анализ и интерпретация результатов, написание текста; Голобородова И.В. - разработка дизайна, набор материала, анализ и интерпретация результатов, написание текста; Стародубова А.В. - разработка дизайна, набор материала, анализ и интерпретация результатов, написание текста; Кочетков А.И. - разработка дизайна, набор материала, анализ и интерпретация результатов, написание текста; Кикнадзе Т.Д. - разработка дизайна, набор материала, анализ и интерпретация результатов, написание текста; Галстян Г.Р. - разработка дизайна, набор материала, анализ и интерпретация результатов, написание текста.

\section{СПИСОК ЛИТЕРАТУРЫ | REFERENCES}

1. Global Age Watch Index 2015. Insight Report, Help Age International; 2015 [cited 2019 March 15]. Available from: http://www.helpage.org/global-agewatch

2. WHO. The epidemiology and impact of dementia: current state and future trends. Geneva: World Health Organization; 2015 [updated 2017 March 8]. Available from: https://www.who.int/mental_health/ neurology/dementia/dementia_thematicbrief_epidemiology.pdf

3. World Alzheimer Report 2015. The global impact of dementia: an analysis of prevalence, incidence, cost and trends. London: Alzheimer's Disease International; 2015 [cited 2019 March 17]. Available from: https://www.alz.co.uk/research/WorldAlzheimerReport2015.pdf

4. Fratiglioni L, De Ronchi D, Agüero-Torres H. Worldwide prevalence and incidence of dementia. Drugs and Aging. 1999;15(5):365-375. doi: https://doi.org/10.2165/00002512-199915050-00004

5. World Alzheimer Report 2014. Dementia and risk reduction: an analysis of protective and modifiable risk factors. London: Alzheimer's Disease International; 2014 [updated 2017 March 8]. Available from: http://www.alz.co.uk/research/WorldAlzheimerReport2014.pdf

6. Яхно Н.Н., Захаров В.В. Легкие когнитивные нарушения в пожилом возрасте // Неврологический журнал. - 2004 - Т. 9. - №1. - С. 4-8. [Yahno NN, Zaharov W. Mild cognitive disorders in the elderly. Journal of neurology. 2004;9(1):4-8. (In Russ.)]

7. Di Carlo A, Baldereschi M, Amaducci L, et al. Cognitive impairment without dementia in older people: prevalence, vascular risk factors, impact on disability. The Italian Longitudinal Study on Aging. J Am Ger Soc. 2000;48(7):775-782. doi: https://doi.org/10.1111/j.1532-5415.2000.tb04752.x

8. Wentzel C, Rockwood K, MacKnight C, et al. Progression of impairment in patients with vascular cognitive impairment without dementia. Neurology. 2001;57(4):714-716. doi: https://doi.org/10.1212/WNL.57.4.714

9. Busse A, Bischkopf J, Riedel-Heller SG, Angermeyer MC. Mild cognitive impairment: prevalence and incidence according to different diagnostic criteria. Results of the Leipzig Longitudinal Study of the Aged (LEILA 75+). Br J Psych. 2003;182:449-454

10. IDF Diabetes Atlas, 8th edition. Brussels: International Diabetes Federation; 2017 [cited 2019 March 17]. Available from: https:// www.idf.org/e-library/epidemiologyresearch/diabetes-atlas/134-idfdiabetes-atlas-8th-edition.html

11. Umegaki H. Type 2 diabetes as a risk factor for cognitive eimpairment: current in sights. Clin/nterv Aging. 2014;9:1011-1019. doi: https://doi.org/10.2147/CIA.S48926
12. Zhang J, Chen C, Hua S, et al. An updated meta-analysis of cohort studies: diabetes and risk of Alzheimer's disease. Diabetes Res Clin Pract. 2017;124:41-47. doi: https://doi.org/10.1016/j.diabres.2016.10.024

13. Остроумова О.Д., Суркова Е.В., Ших Е.В., и др. Когнитивные нарушения у больных сахарным диабетом 2 типа: распространенность, патогенетические механизмы, влияние противодиабетических препаратов // Сахарный диабет. 2018. - T. 21. - №4. - C. 307-318. [Ostroumova OD, Surkova EV, Chikh EV, et al. Cognitive impairment in patients with type 2 diabetes mellitus: prevalence, pathogenetic mechanisms, the effect of antidiabetic drugs. Diabetes Mellitus. 2018;21(4):307-318. (In Russ.)] doi: https://doi.org/10.14341/DM9660

14. Cheng $\mathrm{G}$, Huang $\mathrm{C}$, Deng $\mathrm{H}$, Wang $\mathrm{H}$. Diabetes as a risk factor for dementia and mild cognitive impairment: a meta-analysis of longitudinal studies. Intern Med J. 2012;42(5):484-491. doi: https://doi.org/10.1111/j.1445-5994.2012.02758.x

15. Gudala K, Bansal D, Schifano F, Bhansali A. Diabetes mellitus and risk of dementia: a meta-analysis of prospective observational studies. J Diabetes Investig, 2013;4(6):640-650. doi: https://doi.org/10.1111/jdi.12087

16. Biessels GJ, Staekenborg S, Brunner E, et al. Risk of dementia in diabetes mellitus: a systematic review. The Lancet Neurology. 2006;5(1):64-74. doi: https://doi.org/10.1016/s1474-4422(05)70284-2

17. Lu FP, Lin KP, Kuo HK. Diabetes and the risk of multi-system aging phenotypes: a systematic review and meta-analysis. Plos One. 2009;4(1):41-44. doi: https://doi.org/10.1371/journal.pone.0004144

18. Biessels GJ, Despa F. Cognitive decline and dementia in diabetes mellitus: mechanisms and clinical implications. Nat Rev Endocrinol. 2018;14(10):591-604. doi: https://doi.org/10.1038/s41574-018-0048-7

19. Luchsinger JA, Reitz C, Patel B, et al. Relation of diabetes to mild cognitive impairment. Arch Neurol. 2007;64(4):570-575. doi: https://doi.org/10.1001/archneur.64.4.570

20. Roberts RO, Knopman DS, Geda YE, et al. Association of diabetes with amnestic and nonamnestic mild cognitive impairment. Alzheimers Dement. 2014;10(1):18-26. doi: https://doi.org/10.1016/j.jalz.2013.01.001

21. Cooper C, Sommerlad A, Lyketsos CG, Livingston G. Modifiable predictors of dementia in mild cognitive impairment: a systematic review and meta-analysis. Am J Psychiatry. 2015;172(4):323-334. doi: https://doi.org/10.1176/appi.ajp.2014.14070878 
22. Li JQ, Tan L, Wang HF, et al. Risk factors for predicting progression from mild cognitive impairment to Alzheimer's disease: a systematic review and meta-analysis of cohort studies. J Neurol Neurosurg Psychiatry. 2016;87(5):476-484. doi: https://doi.org/10.1136/jnnp-2014-310095

23. Haroon NN, Austin PC, Shah B, et al. Risk of dementia in seniors with newly diagnosed diabetes: a population-based study. Diabetes Care. 2015;38(10):1868-1875. doi: https://doi.org/10.2337/dc15-0491

24. Secnik J, Cermakova P, Fereshtehnejad SM, et al. Diabetes in a large dementia cohort: clinical characteristics and treatment from the Swedish dementia registry. Diabetes Care. 2017;40(9):1159-1166. doi: https://doi.org/10.2337/dc16-2516

25. Bordier L, Doucet J, Boudet J, Bauduceau B. Update on cognitive decline and dementia in elderly patients with diabetes. Diabetes Metab. 2014;40(5):331-337. doi: https://doi.org/10.1016/j.diabet.2014.02.002

26. Алгоритмы специализированной медицинской помощи больным сахарным диабетом / Под ред. И.И. Дедова, М.В. Шестаковой, А.Ю. Майорова. 9-й вып., дополн. - М.: УП ПРИНТ, 2019. 214 c. [Standards of specialized diabetes care. Ed by II Dedov, MV Shestakova, AYu Mayorov. 9th ed, updated. Moscow: UP PRINT; 2019. 214 p. (In Russ.)] doi: https://doi.org/10.14341/DM221S1

27. Abdelhafiz AH, Rodríguez-Mañas L, Morley JE, Sinclair AJ. Hypoglycemia in older people - a less well recognized risk factor for frailty. Aging and disease. 2015;6(2):156-167. doi: https://doi.org/10.14336/AD.2014.0330

28. Bramlage P, Gitt AK, Binz C, et al. Oral antidiabetic treatment in type-2 diabetes in the elderly: balancing the need for glucose control and the risk of hypoglycemia. Cardiovasc Diabetol. 2012;11:122 doi: https://doi.org/10.1186/1475-2840-11-122

29. Kaewput W, Thongprayoon C, Varothai N, et al. Prevalence and associated factors of hospitalization for dysglycemia among elderly type 2 diabetes patients: a nationwide study. World J Diab. 2019;10(3):212-223. doi: https://doi.org/10.4239/wjd.v10.i3.212

30. Quartuccio M, Buta B, Kalyani RR. Comparative effectiveness for glycemic control in older adults with diabetes. Curr Geri Rep. 2017;6(3):175-186. doi: https://doi.org/10.1007/s13670-017-0215-z

31. Chen Y, Liu Z, Yu Y, et al. Effect of recurrent severe hypoglycemia on cognitive performance in adult patients with diabetes: a meta-analysis. J Huazhong Univ Sci Technol. 2017;37(5):642-648. doi: https://doi.org/10.1007/s11596-017-1784-y

32. Aung PP, Strachan MW, Frier BM, et al.; Edinburgh Type 2 Diabetes Study Investigators. Severe hypoglycemia and latelife cognitive ability in older people with type 2 diabetes: the Edinburgh type 2 diabetes study. Diabet Med. 2012;29(3):328-336. doi: https://doi.org/10.1111/j.1464-5491.2011.03505.x

33. Bruce DG, Davis WA, Casey GP, et al. Severe hypoglycaemia and cognitive impairment in older patients with diabetes: the Fremantle diabetes study. Diabetologia. 2009;52(9):1808-1815. doi: https://doi.org/10.1007/s00125-009-1437-1

34. Mattishent K, Loke YK. Bi-directional interaction between hypoglycaemia and cognitive impairment in elderly patients treated with glucose-lowering agents: a systematic review and meta-analysis. Diabetes, Obesity, Metab. 2016;18(2):135-141. doi: https://doi.org/10.1111/dom.12587

35. Yaffe K, Falvey CM, Hamilton N, et al. Association between hypoglycemia and dementia in a biracial cohort of older adults with diabetes mellitus. JAMA Intern Med. 2013;173(14):1300-1306. doi: https://doi.org/10.1001/jamainternmed.2013.6176

36. Chin SO, Rhee SY, Chon S, et al. Hypoglycemia is associated with dementia in elderly patients with type 2 diabetes mellitus: an analysis based on the Korea National Diabetes Program Cohort. Diabetes Res Clin Pract. 2016;122:54-61. doi: https://doi.org/10.1016/j.diabres.2016.09.027

37. Feinkohl I, Aung PP, Keller M, et al. Severe hypoglycemia and cognitive decline in older people with type 2 diabetes: the Edinburgh type 2 diabetes study. Diabetes Care. 2014;37(2):507-515. doi: https://doi.org/10.2337/dc13-1384

38. Whitmer RA, Karter AJ, Yaffe K, et al. Hypoglycemic episodes and risk of dementia in older patients with type 2 diabetes mellitus. JAMA. 2009;301(15):1565-1572. doi: https://doi.org/10.1001/jama.2009.460

39. Mehta HB, Mehta V, Goodwin JS. Association of hypoglycemia with subsequent dementia in older patients with type 2 diabetes mellitus. J Gerontol A Biol Sci Med Sci. 2017;72(8):1110-1116. doi: https://doi.org/10.1093/gerona/glw217
40. Васенина E.E., Левин О.С. Когнитивные нарушения у пациентов с сахарным диабетом 2 типа // Эффективная фармакотерапия. 2016. - №3. - C. 40-47. [Vasenina EE, Levin OS. Cognitive impairment in patients with type 2 diabetes mellitus. Effective pharmacotherapy. 2016;(3):40-47. (In Russ.)]

41. Mohseni S. Neurologic damage in hypoglycemia. Hand Clin Neurol. 2014;126:513-532. doi: https://doi.org/10.1016/B978-0-444-53480-4.00036-9

42. Ouyang YB, He QP, Li PA, et al. Is neuronal injury caused by hypoglycemic coma of the necrotic or apoptotic type? Neurochem Res. 2000;25(5):661-667. doi: https://doi.org/10.1023/A:1007563104170

43. Ferrand-Drake M, Zhu C, Gido G, et al. Cyclosporin A prevents calpain activation despite increased intracellular calcium concentrations, as well as translocation of apoptosis-inducing factor, cytochrome $\mathrm{c}$ and caspase-3 activation in neurons exposed to transient hypoglycemia. J Neurochem. 2003;85(6):1431-1442. doi: https://doi.org/10.1046/j.1471-4159.2003.01794.x

44. Joseph A, Antony S, Paulose CS. Increased glutamate receptor gene expression in the cerebral cortex of insulin induced hypoglycemic and streptozotocininduced diabetic rats. Neuroscience. 2008;156(2):298-304. doi: https://doi.org/10.1016/j.neuroscience.2008.07.022

45. Auer RN. Hypoglycemic brain damage. Metab Brain Dis. 2004;19(3-4):169-175. doi: https://doi.org/10.1023/B:MEBR.0000043967.78763.5b

46. Suh SW, Gum ET, Hamby AM, et al. Hypoglycemic neuronal death is triggeredby glucose reperfusion and activation of neuronal NADPH oxidase. J Clin Invest. 2007;117(4):910-918. doi: https://doi.org/10.1172/JCl30077

47. Tkacs NC, Dunn-Meynell AA, Levin BE. Presumed apoptosis and reduced arcuate nucleus neuropeptide $Y$ and pro-opiomelanocortin mRNA in non-coma hypoglycemia. Diabetes. 2000;49(5):820-826. doi: https://doi.org/10.2337/diabetes.49.5.820

48. Robinson R, Krishnakumar A, Paulose CS. Enhanced dopamine D1 and D2 receptor gene expression in the hippocampus of hypoglycaemic and diabetic rats. Cell Mol Neurobiol. 2009;29(3):365-372. doi: https://doi.org/10.1007/s10571-008-9328-4

49. Suh SW, Won SJ, Hamby AM, et al. Decreased brain zinc availability reduces hippocampal neurogenesis in mice and rats. J Cereb Blood Flow Metab. 2009;29(9):1579-1588. doi: https://doi.org/10.1038/jcbfm.2009.80

50. Languren G, Montiel T, Julio-Amilpas A, Massieu L. Neuronal damage and cognitive impairment associated with hypoglycemia: an integrated view. Neurochem Int. 2013;63(4):331-343. doi: https://doi.org/10.1016/j.neuint.2013.06.018

51. Smith L, Chakraborty D, Bhattacharya P, et al. Exposure to hypoglycemia and risk of stroke. Ann N Y Acad Sci. 2018;1431(1):25-34. doi: https://doi.org/10.1111/nyas.13872

52. Katon W, Pedersen HS, Ribe AR, et al. Effect of depression and diabetes mellitus on the risk for dementia: a national populationbased cohort study. JAMA Psychiatry. 2015;72(6):612-619. doi: https://doi.org/10.1001/jamapsychiatry.2015.0082

53. Punthakee $Z$, Miller ME, Launer LJ, et al.; ACCORD Group of Investigators; ACCORD-MIND Investigators. Poor cognitive function and risk of severe hypoglycemia in type 2 diabetes: post hoc epidemiologic analysis of the ACCORD trial. Diabetes Care. 2012;35(4):787-793. doi: https://doi.org/10.2337/dc11-1855

54. Abbatecola AM, Bo M, Armellini F, et al. Tighter glycemic control is associated with ADL physical dependency losses in older patients using sulfonylureas or mitiglinides: results from the DIMORA study. Metabolism. 2015;64(11):1500-1506. doi: https://doi.org/10.1016/j.metabol.2015.07.018

55. Prinz N, Stingl J, Dapp A, et al. High rate of hypoglycemia in 6770 type 2 diabetes patients with comorbid dementia: a multicenter cohort study on 215,932 patients from the German/Austrian Diabetes Registry. Diabetes Res Clin Pract. 2016;112:73-81. doi: https://doi.org/10.1016/j.diabres.2015.10.026

56. Feil DG, Rajan M, Soroka O, et al. Risk of hypoglycemia in older veterans with dementia and cognitive impairment: implications for practice and policy. J Am Geriatr Soc. 2011;59(12):2263-2272. doi: https://doi.org/10.1111/j.1532-5415.2011.03726.x

57. McMillan JM, Mele BS, Hogan DB, Leung AA. Impact of pharmacological treatment of diabetes mellitus on dementia risk: systematic review and meta-analysis. BMJ Open Diab Res Care. 2018;6(1):e000563. doi: https://doi.org/10.1136/bmjdrc-2018-000563 
58. Bruce DG, Davis WA, Nelson M, et al. Severe hypoglycaemia does not explain the relationship between long duration insulin therapy and late-life cognitive impairent in type 2 diabetes: the Fremantle Diabetes Study. Alzheimer's and dementia. 2014;10:295 doi: https://doi.org/10.1016/j.jalz.2014.04.490

59. $\mathrm{KH} \mathrm{H}$, Jeon JY, Kim HJ. Severe hypoglycemia and risk of dementia in person with diabetes mellitus. Journal of Diabetes Investigation. 2017:8:35.

60. Whitmer R, Quesenberry Jr C, Allison J. Anti-hyperglycemic therapy and risk of dementia: a new user cohort study. Alzheimer's and dementia. 2013;1:136. doi: https://doi.org/10.1016/j.jalz.2013.04.077

61. Huang CC, Chung CM, Leu HB, et al. Diabetes mellitus and the risk of Alzheimer's disease: a nationwide population-based study. PLoS One. 2014;9(1):e87095. doi: https://doi.org/10.1371/journal.pone.0087095

62. Hsu CC, Wahlqvist ML, Lee MS, Tsai HN. Incidence of dementia is increased in type 2 diabetes and reduced by the use of sulfonylureas and metformin. J Alzheimers Dis. 2011;24(3):485-493. doi: https://doi.org/10.3233/JAD-2011-101524

63. Kuan YC, Huang KW, Lin CL, et al. Effects of metformin exposure on neurodegenerative diseases in elderly patients with type 2 diabetes mellitus. Prog Neuropsychopharmacol Biol Psychiatry. 2017;79(Pt B):77-83. doi: https://doi.org/10.1016/j.pnpbp.2017.06.002

64. Ng TP, Feng L, Yap KB, et al. Longterm metformin usage and cognitive function among older adults with diabetes. J Alzheimer's Disease. 2016:41(1):61-68. doi: https://doi.org/10.3233/JAD-131901

65. Weinstein G, Davis-Plourde KL, Conner S, et al. Association of metformin, sulfonylurea and insulin use with brain structure and function and risk of dementia and Alzheimer's disease: Pooled analysis from 5 cohorts. PLoS ONE. 2019;14(2):e0212293. doi: https://doi.org/10.1371/journal.pone.0212293

66. American Diabetes Association. Management of Diabetes in Pregnancy: Standards of Medical Care in Diabetes-2019. In: Standards of Medical Care in Diabetes 2019. Diabetes Care 2019;42(Suppl. 1):S1-S183. doi: https://doi.org/10.2337/dc19-S014

67. Davies MJ, D'Alessio DA, Fradkin J, et al. Correction to: management of hyperglycaemia in type 2 diabetes, 2018. A consensus report by the American Diabetes Association (ADA) and the European Association for the Study of Diabetes (EASD). Diabetologia. 2019;62(5):873. doi: https://doi.org/10.1007/s00125-019-4845-x

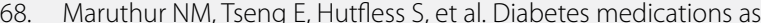
monotherapy or metformin-based combination therapy for type 2 diabetes: a systematic review and meta-analysis. Ann Intern Med.
2016:164(11):740-751. doi: https://doi.org/10.7326/m15-2650

69. Leonard CE, Han X, Brensinger CM, et al. Comparative risk of serious hypoglycemia with oral antidiabetic monotherapy: a retrospective cohort study. Pharmacoepidemiol Drug Safety. 2018;27(1):9-18. doi: https://doi.org/101102/pds.4337

70. Kirpichnikov D, MCFarlane SI, Sowers JR. Metformin: an update. Ann Intern Med. 2002;137(1):25-33.

doi: https://doi.org/10.7326/0003-4819-137-1-200207020-00009

71. Li J, Benashski SE, Venna VR, McCullough LD. Effects of metformin in experimental stroke. Stroke. 2010;41(11):2645-2652 doi: https://doi.org/10.1161/STROKEAHA.110.589697

72. Aggarwal N, SinglaA, Mathieu C, et al. Metformin extended-release versus immediate-release: an international, randomized, doubleblind, head-to-head trial in pharmacotherapy-naïve patients with type 2 diabetes. Diabetes Obes Metab. 2018;20(2):463-467. doi: https://doi.org/10.1111/dom.13104

73. Campbell JM, Stephenson MD, de Courten B, et al. Metformin use associated with reduced risk of dementia in patients with diabetes: a systematic review and meta-analysis. J Alzheimer's Disease. 2018;65(4):1225-1236. doi: https://doi.org/10.3233/JAD-180263

74. Guo M, Mi J, Jiang QM, et al. Metformin may produce antidepressant effects through improvement of cognitive function among depressed patients with diabetes mellitus. Clin Exp Pharmacol Physiol. 2014;41(9):650-656. doi: https://doi.org/10.1111/1440-1681.12265

75. Markowicz-Piasecka M, Sikora J, Szydłowska A, et al. Metformin - a future therapy for neurodegenerative diseases. Pharm Res. 2017;34(12):2614-2627. doi: https://doi.org/10.1007/s11095-017-2199-y

76. Herath PM, Cherbuin N, Eramudugolla R, Anstey KJ. The effect of diabetes medication on cognitive function: evidence from the PATH through life study. BioMed Res Int. 2016;2016:7208429. doi: https://doi.org/10.1155/2016/7208429

77. Patil SP, Jain PD, Ghumatkar PJ, et al. Neuroprotective effect of metformin in Parkinsons disease in mice. Neuroscience. 2014;277:747-754. doi: https://doi.org/10.1016/j.neuroscience.2014.07.046

78. Chung M, Chenb Y, Pei D, et al. The neuroprotective role of metformin in advanced glycation end product treated human neural stem cells is AMPK-dependent. Biochimica et Biophysica Acta. 2015;1852:720-731. doi: https://doi.org/10.1016/j.bbadis.2015.01.006

\section{ИНФОРМАЦИЯ ОБ АВТОРАХ [AUTHORS INFO]}

*Остроумова Ольга Дмитриевна, д.м.н., профессор [Olga D. Ostroumova, MD, PhD, Professor]; адрес: 127423, ул. Делегатская, 20/1 [address: 20/1, Delegatskaya st., Moscow, 127423 Russian Federation]; ORCID: https://orcid.org/0000-0002-0795-8225; eLibrary SPIN: 3910-6585; e-mail: ostroumova.olga@mail.ru

Суркова Елена Викторовна, д.м.н., гл.н.с. [Elena V. Surkova, MD, PhD, chief research associate]; ORCID: https://orcid.org/0000-0002-3973-7638; eLibrary SPIN: 7944-3869; e-mail: elenasurkova@mail.ru Голобородова Ирина Васильевна, к.М.н., доцент [Irina V. Goloborodova, MD, PhD, associate professor]; ORCID: https://orcid.org/0000-0003-4583-6330; eLibrary SPIN: 8230-1487;e-mail: giv55555@rambler.ru

Стародубова Антонина Владимировна, А.М.н. [Antonina V. Starodubova, MD, PhD]; ORCID: https://orcid.org/0000-0001-9262-9233; e-mail: mailbox@ion.ru

Кочетков Алексей Иванович, к.M.H., H.c. [Alexey I. Kochetkov, MD, PhD, research associate]; ORCID: https://orcid.org/0000-0001-5801-3742; eLibrary SPIN: 9212-6010; e-mail: ak_info@list.ru Кикнадзе Тамара Давидовна, врач-терапевт [Tamara D. Kiknadze, therapist];

ORCID: https://orcid.org/0000-0003-2951-2117; eLibrary SPIN: 1558-8992; e-mail: kostawa.toma@yandex.ru Галстян Гагик Радикович, д.м.Н., профессор [Gagik R. Galstyan, MD, PhD, Professor]; ORCID: https://orcid.org/0000-0001-6581-4521; eLibrary SPIN: 9815-7509; e-mail: galstyangagik964@gmail.com

\section{ЦИТИРОВАТЬ:}

Остроумова О.Д., Суркова Е.В., Голобородова И.В., Стародубова А.В., Кочетков А.И., Кикнадзе Т.Д., Галстян Г.Р. Гипогликемии и риск когнитивных нарушений и деменции у больных пожилого и старческого возраста с сахарным диабетом 2 типа // Сахарный диабет. — 2020. — T. 23. — №1. — C. 72-87. doi: 10.14341/DM10202

\section{TO CITE THIS ARTICLE:}

Ostroumova OD, Surkova EV, Goloborodova IV, Starodubova AV, Kochetkov Al, Kiknadze TD, Galstyan GR. Hypoglycemia and the risk of cognitive impairment and dementia in elderly and senile patients with type 2 diabetes. Diabetes Mellitus. 2020;23(1):72-87. doi: 10.14341/DM10202 